\title{
APUNTES SOBRE EL SISTEMA ITALIANO DE LAS CIRCUNSTANCIAS DEL DELITO: EVOLUCIÓN DEL PENSAMIENTO PENAL MODERNO Y APROXIMACIÓN AL DERECHO ACTUAL.
}

\author{
Manuel José ARIAS EIBE \\ DOCTOR EN DERECHO \\ UNIVERSIDAD DE A CORUÑA
}

s u m a r i o

I. Introducción. II. Caracteres generales del modelo italiano actual de circunstancias modificativas de la responsabilidad penal. III. Las circunstancias agravantes comunes o generales. IV. Las circunstancias atenuantes comunes o generales. V. Las circunstancias atenuantes genéricas. VI. La imputación de las circunstancias modificativas de la responsabilidad criminal. VII. El juicio de comparación o equivalencia. Bibliografía.

$r$ e $s \quad u$ e $n$

Si bien la presencia de las circunstancias modificativas de la responsabilidad criminal es un lugar común en la práctica totalidad de las legislaciones penales modernas, no existe un único modelo o sistema. Existen así dos grandes modelos teóricos o sistemas legales de configuración de las circunstancias modificativas de la responsabilidad criminal: el denominado sistema legal de «circunstancias generales», que integra las referidas circunstancias atenuantes y agravantes en la Parte General, las cuales, al menos en principio, proyectarían su ámbito sobre todos los delitos y, en segundo lugar, el sistema que incluye las circunstancias atenuantes y agravantes en la Parte Especial, denominado modelo o sistema legal de «circunstancias específicas», proyectando éstas su eficacia sobre un determinado delito o grupo de delitos. En realidad, si bien las diferentes legislaciones se inclinan por uno u otro modelo, en la práctica no existen sistemas puros, por lo que la doctrina que se ha ocupado de la materia habla de la existencia de sistemas mixtos con tendencia en uno $\mathrm{u}$ otro sentido. El modelo italiano de circunstancias del delito es uno de los más perfectos en la actualidad sino el más completo- mientras que la doctrina italiana ha desarrollado a su alrededor una completa teoría general que permite que nos podamos referir a este modelo como de auténtico sistema de circunstancias. En lo que sigue haremos una breve referencia a las características generales de dicho sistema así como un breve esbozo de la evolución en Italia del pensamiento penal moderno sobre la graduabilidad de injusto y culpabilidad. 


\section{Introducción.}

En la evolución del pensamiento dogmático italiano, desde los comienzos del Derecho penal moderno hasta la actualidad, en relación con las circunstancias del delito, son de destacar los planteamientos de figuras como la del precursor y reformista BECCARIA (I738-I794), quien reaccionando frente al inhumano sistema penal del momento, y rechazando el criterio subjetivo a la hora de graduar los delitos, se centró en el criterio del «daño a la sociedad» para la medida de los mismos ${ }^{\mathrm{I}}$, al contrario de lo que harían ya dentro de la Ciencia penal de la Ilustración otros autores como FILANGIERI (1752-1788), quien atenderá, por el contrario, al elemento moral antes que al externo ${ }^{2}$ o ROMAGNOSI (1761-

\footnotetext{
${ }^{\text {I }}$ Este planteamiento de BECCARIA será posteriormente seguido y desarrollado por CARMIGNANI y CARRARA dentro ya de la Escuela Clásica. Efectivamente, para BECCARIA, la gravedad de los delitos debe apreciarse en relación con el daño social producido por los mismos antes que atendiendo a criterios subjetivos defendidos por otros autores, como la malicia moral del hecho en sí mismo, la entidad del pecado cometido, o el rango o nivel social del ofensor o víctima del delito. El autor milanés no consideraba trascendentes los criterios subjetivos del agente como su intención a la hora de valorar la gravedad del delito, antes al contrario, sostenía que atender a tales criterios subjetivos resultaba enormemente perturbador, dado que cada persona, sus ideas, pasiones y circunstancias resultan distintas, y por ello no resultaba posible, ni materialmente práctico, atender a parámetros estrictamente subjetivos en esta materia. En definitiva, para BECCARIA habría de ser el daño social causado la verdadera medida de la gravedad de los delitos y de la consiguiente y proporcionada dureza de la sanción penal a imponer en cada caso. Por otra parte, para este autor la eficacia de las penas no iba unida a su dureza, sino que, antes al contrario, lo verdaderamente trascendente a estos efectos era la seguridad, inexorabilidad y certeza de imposición, antes que su dureza e indeterminada aplicación; es decir, era preferible -y más eficaz- una pena suave pero cuya imposición se sentía ineludible, antes que una pena muy severa, pero cuya aplicación resultaba incierta. Respecto a los fines de la pena, para este autor no se debería perseguir, en sí mismo, el castigo del agente por haber obrado mal, sino castigar para evitar que el sujeto volviera a causar daño social -prevención especialy al mismo tiempo evitar que los demás sujetos cometan al mismo tiempo delitos causando daños sociales -función ejemplificadora o de prevención general-. Para ello, las penas a aplicar deberían ser proporcionadas, causando el menor daño posible al sujeto, y más que de aplicar la pena «merecida» se trataba de aplicar una pena que resultara «util» o «eficaz» desde una perspectiva preventiva especial y general. La pena justa, para BECCARIA, es la pena eficaz y útil para evitar futuros delitos. BECCARIA defendía de forma especialmente intensa la necesidad de que la pena fuera proporcional al delito y a su gravedad, y asimismo debería ser acompasada a la naturaleza del delito cometido, ya que ante dos delitos de diferente gravedad que tuviesen igual pena, el sistema inclinaría al delincuente a la comisión de delitos especialmente graves, de los que podría obtener un mayor beneficio o satisfacción con el mismo coste. Respecto a la pena de muerte, y como es sabido, BECCARIA considera que tal pena resulta injusta, además de ineficaz e innecesaria en la mayoría de los casos, propugnando, por el contrario, penas duraderas que provocan un más prolongado efecto disuasorio en la comunidad antes que la pena de muerte que, si bien produce un efecto más impactante, éste es más pasajero. BECCARIA tan sólo admitirá la pena de muerte en el excepcional supuesto de que el sujeto aún privado de libertad siga suponiendo por sus relaciones y poder un peligro para el Estado. Por último, para BECCARIA es preferible la prevención mediante buenas leyes y educación cívica, a la sanción.

${ }^{2}$ Gaetano FILANGIERI, dentro del penalismo ilustrado, es un autor que presenta cierta afinidad con BECCARIA, salvo en lo tocante a la posición mantenida respecto a la pena de muerte, ya que si como hemos visto BECCARIA era sustancialmente abolicionista -salvo en excepcionales supuestosFILANGIERI, por el contrario, era firme defensor de la misma. No obstante aquella diferencia, como señala SPIRITo, U.: Storia del diritto penale italiano, da Cesare Beccaria ai giorni nostri, $3^{\mathrm{a}}$ ed. Firenze, I974, p. 59 ss., del mismo modo que BECCARIA fue el primer penalista en llevar a cabo en el ámbito de los principios ilustrados las líneas fundamentales de un sistema penal, FILANGIERI fue a su vez quien por primera vez elaboró y profundizó en aquel sistema un tratado completo, complejo y orgánico, donde los principios generales mencionados por BECCARIA fueron llevados hasta casi la determinación concreta de un Código, presentando singular relevancia las aportaciones que con base en las teorías contractualistas desarrolló en orden a la construcción del que pudiera ser denominado el primer gran sistema moderno del derecho penal. Para el autor napolitano la pena tenía una
}

Redur 4 / 2006 
1835), que se centrará en el concepto de «spinta criminosa», es decir, en la utilidad que el delincuente quiso obtener del delito, así como en la facilidad de comisión y esperanza de impunidad 3 ; dentro ya de la Escuela Clásica, Rossi (I787 - I848), por su parte, centrará su

función estrictamente utilitaria: la defensa legítima de la sociedad creada por los individuos, función para la cual la pena, al igual que había sucedido con BECCARIA, debía ser proporcionada al delito y su límite mismo era su necesidad. FILANGIERI reconocía que el delito podía ser más o menos grave en función de la concurrencia de circunstancias que pusieran de manifiesto una mayor menor disposición del sujeto a volver a cometer el mismo $u$ otro delito, es decir, en función de que el sujeto estuviera dispuesto a volver a violar el pacto social. Al mismo tiempo distinguía en el momento de la comisión del delito entre la calidad y el grado, considerando que la calidad es el pacto que se viola y el grado la mayor o menor maldad manifestada al violarlo. Para FILANGIERI la pena debía ser proporcional al resultado de combinar calidad y grado en el caso concreto, de suerte que del mismo modo que el desvalor del delito dependía de la calidad (pacto violado) y el grado (mayor o menor maldad), a mayor desvalor del delito, mayor pena. La referencia que FILANGIERI hacía a la calidad del delito es pareja al actual concepto de bien jurídico afectado por el delito, mientras que el grado del mismo se refiere a los modernos conceptos de injusto y culpabilidad como magnitudes graduables. Profundizando en la distinción conceptual de calidad y grado del delito, FILANGIERI propone que no se confundan las circunstancias con los elementos que determinan un cambio en la calidad y naturaleza del mismo; mientras que los elementos del delito configurarían de manera rígida e inflexible la calidad del mismo, las circunstancias configurarían su cantidad pero de un modo flexible, eventual y variable. Para el autor napolitano, circunstancias modificativas de la responsabilidad criminal lo son tan sólo aquellas que sin alterar la calidad del delito, le otorgan una mayor o menor gravedad y una mayor o menor punibilidad. FILANGIERI, de forma congruente con su distinción entre calidad y grado, proponía una reforma global del sistema legislativo penal, de suerte que la ley debería contemplar una pena para cada delito en función del pacto social violado en cada caso concreto y de su gravedad (no es lo mismo, obviamente, que nos hallemos ante un robo que ante un asesinato, y por ello las penas respectivas deben ser diferentes en función de la calidad, esto es, del bien jurídico, respectivamente afectado), pero al mismo tiempo, la ley debía determinar una distinción entre seis diferentes grados de pena, relacionados con una subdivisión entre tres grados de dolo, y tres grados de culpabilidad; de esta suerte FILANGIERI pretendía, por una parte, la determinación legislativa del desvalor de cada delito, y al mismo tiempo, la determinación dentro de cada delito de su respectiva gravedad en función de las concretas y peculiares circunstancias concurrentes; de esta suerte, el propio FILANGIERI establecía que cuando la acción había tenido lugar a consecuencia del ímpetu de la pasión, el grado del dolo habría que reconocerlo ínfimo; del mismo modo, cuando la causa impelente era débil, o la acción se había cometido a sangre fría, y con madura reflexión, el grado del dolo era el mediano, y por último, cuando se había cometido la acción sin causa o con causa, pero con perfidia o con atroz ensañamiento, el grado del dolo habría de considerársele máximo, y del mismo modo, y con criterios similares diferenciaba entre los diferentes grados de culpa. Vid. Filangieri, G.: Ciencia de la legislación, escrita en italiano por Cayetano Filangieri, traducida al castellano por Jaime Rubio, $3^{a}$ ed., corr. y añadida con discursos analíticos en cada libro, Ed. Imp. de Núñez, Madrid, I822; CoTTA, S.: Gaetano Filangieri e il problema della legge, Ed.: G. Giappichelli, Torino, I954.

${ }^{3}$ RoMAGNOSI sostenía que lo principal y más importante para la sociedad era la prevención del delito (a través de una dinámica moral preventiva), antes que la represión; para el profesor de la Universidad de Pavía, la pena es una «contro-spinta penale alla spinta criminosa...», Vid. CATTANEO, N.A.: Pena diritto e dignità umana: saggio sulla filosofia del diritto penale, Ed. Giappichelli, Torino, I998. Para Romagnosi, el Derecho penal era un Derecho natural inmutable anterior incluso a las convenciones humanas, tratándose de un derecho de defensa, frente a la permanente amenaza derivada de los defectos de la naturaleza humana, del impulso criminal permanente, y cuya finalidad era la conservación de la paz y el bienestar de la sociedad a través de la neutralización del impulso delictivo por medio de la pena. El Derecho penal se ejercita por la sociedad para su defensa como último remedio cuando la prevención fracasa; y antes que aspirar a vengar o punir como castigo su fin es la prevención del delito a través del temor por medio de las penas, cuya especie, calidad y cantidad debe ser proporcional a la calidad e intensidad del impulso criminoso, en una suerte de controspinta morale a la spinta criminosa. ROMAGNOSI en su obra Genesi del diritto penale, se apartó un tanto del pensamiento de FILANGIERI, en especial en lo relativo a la distinción de la graduación del dolo efectuada por el autor napolitano. Para RomAgnosi la medida o determinación de la pena presentaba una íntima conexión con el «impulso criminoso», concepto que a su vez también 
atención en la infracción del deber violado por el sujeto ${ }^{4}$ y CARRARA (I805-1888), tras sostener que cada delito tiene su propia cualidad, sostiene que cada uno de ellos debe llevar pareja diversa medida de imputación, separando entre cualidad o cantidad de los delitos y el grado de la pena, y reconduciendo las circunstancias, en última instancia, a la teoría de la pena 5 .

relacionaba directamente con la cualidad y cantidad. El profesor de Pavía defendía la técnica de que las leyes previeran un máximo y un mínimo de pena para cada delito, dejando así a los jueces un cierto margen de discrecionalidad en la determinación de la misma. En la tarea de elaboración y promulgación de las leyes, el legislador, además de elegir para cada delito concreto una determinada especie o calidad de pena, debería regular también la cantidad de las penas en atención a las circunstancias concurrentes, de suerte que ROMAGNOSI creyó incluso llegar a individualizar el fundamento de la distinción de los delitos calificados y no calificados que no suponían, en su opinión, sino dos variedades de la misma naturaleza y no dos especies diferentes como por el contrario había mantenido FILANGIERI. Al igual que el planteamiento de FILANGIERI tuvo especial repercusión en el Proyecto del código penal para el Reino de Italia, de I806, el pensamiento de Romagnosi tuvo un correlativo influjo en el Proyecto del código penal para el Reino de Italia, de I809, en cuya redacción tuvo una participación personal activa. Sobre el pensamiento de ROMAGNOSI Vid. Belloni, G. A.: Saggi sul Romagnosi, Ed. Fratelli Bocca, Milano, i940; Del Vecchio, G.: «Giandomenico Romagnosi nel primo centenario della sua morte: discorso letto nella R. Universitá di Parma il 9 settembre I935 per il X Congresso Nazionale di Filosofia», en Rivista Internazionale di Filosofia del Diritto, $3^{\mathrm{a}}$ ed. Roma, I938; Romagnosi, G.D.: Genesi del diritto penale, Parte Seconda, per Francesco Sanvito, Milano, I857, p. 709 y ss; Romagnosi, G.D.: Génesis del Derecho Penal, traducción de Carmelo González Cortina y Jorge Guerrero, Ed.: Temis, Bogotá, I.956.

4 Rossi, en su Trattato di diritto penal, parte de que es al legislador al que corresponde la determinación de los elementos esenciales del delito, la concreción y determinación de la pena, la de las circunstancias agravantes del delito, de los hechos excusantes, los determinantes de una menor gravedad y su respectiva repercusión punitiva; ahora bien, siendo ello así, lo cierto es que RosSI acaba afirmando que el legislador no puede contemplar todos los supuestos que la vida real puede presentar, y por ello acaba reconociendo que el legislador debe reconocer al Juez un poder prudencial de intervención, incluso en aquellos casos en los que la ley hubiera silenciado determinadas circunstancias excusantes, todo ello siempre que se encuentre presente una menor culpabilidad por parte del sujeto; la regla general será, no obstante, que el legislador debe establecer un maximum y un minimum de pena para cada delito, dejando al juez la elección entre estos dos términos extremos según las circunstancias, de suerte que incluso cuando exista un amplio margen entre los dos polos de la pena, el legislador podrá también subdividir la pena en grados en función de una diferenciación de la culpabilidad del agente. Vid. Rossi, P.: Tratado de derecho penal, traducido al idioma español por Cayetano Cortés, Ed. Imprenta de José María Repullés, Madrid, I839.

5 Para CARRARA la pena no puede ser arbitraria sino que por el contrario debe someterse a criterios de proporción atendiendo a factores como la calidad y la cantidad en relación con el daño sufrido por el derecho o el peligro causado al mismo; al mismo tiempo, la pena no debe exceder de las necesidades de la tutela, ya que en caso contrario lo que en otros términos podría ser protección se acabará convirtiendo en violación del Derecho y en tiranía, mientras que si la pena se queda corta en relación con las necesidades referidas, supondrá una evidente flaqueza e incumplimiento por parte de los órganos correspondientes. El sistema del delito en CARRARA presenta una conocida bipartición; para el maestro de Pisa desde que el Derecho se ocupa del acto humano en una doble dimensión: la interna y la externa, el estudio del delito se hace desde dos perspectivas diferentes: la fuerza moral y la fuerza física, todo ello en el marco del principio de antijuridicidad. Vid. QUINTERO Olivares, G.: Curso de Derecho Penal, i996, op. cit., p. i62-I63. CARRARA no admite la imputabilidad de una acción donde no concurran todas las fuerzas que constituyen el delito y del mismo modo no admitirá un aumento o disminución de la imputación salvo que haga acto de presencia una variabilidad en la intensidad de las fuerzas que deben estar presentes en la acción analizada. Al mismo tiempo, y siguiendo con la tradición de FILANGIERI y de CARMIGNANI, CARRARA defendió en su Programa que los delitos deben imputarse al sujeto con la debida proporción a su calidad, cantidad, y grado sin dejar al libre arbitrio de los jueces la determinación de la medida de la pena. Para CARrARA la noción de «calidad» se identificaba con el título o clase de delito que le diferenciaba de los demás; a su vez, el concepto de «cantidad» dimanaba del resultado de un juicio de comparación entre la gravedad encontrada en delitos de diversa calidad, tomando como referencia el

Redur 4 / 2006 
criterio del daño social, y más en concreto el daño «inmediato» (la fuerza objetiva física del delito) y daño «mediato» (la fuerza objetiva moral del delito) combinados juntos y, como decimos, desde una perspectiva estrictamente objetiva. Ahora bien, como la realidad práctica no permite que el jurista se quede en el análisis de géneros o especies, sino que debe analizar concretos hechos realizados por individuos, el sistema penal necesitaba además de los conceptos de calidad y cantidad el de grado. De esta suerte, bajo el concepto de «grado» CARRARA tomará en consideración las características individuales y/o subjetivas del hecho, y las propias de la eventual variación de las fuerzas del delito. Así, mientras que la cantidad del delito se mide con la combinación de la fuerza física y de la fuerza moral del delito, atendiendo al daño inmediato y al mediato desde una perspectiva objetiva, el grado del delito se deducía del criterio de la fuerza física y de la fuerza moral del delito, consideradas principalmente en sus elementos, esto es, subjetivamente. Mientras que en el análisis de la cantidad del delito se estudiaba el hecho de forma abstracta y objetiva, esto es, considerado en su especie, en la indagación del grado del delito se tomaba en consideración el hecho subjetivamente, con sus accidentes peculiares en el individual caso concreto analizado. En definitiva, el grado determinaba la eventual modificabilidad de la gravedad concreta del hecho por la presencia de elementos accidentales que peculiarizan subjetivamente en el caso concreto los elementos esenciales o constitutivos. CARRARA admitía que la variación del grado podía afectar a la imputabilidad, admitiendo que cuando faltara la imputabilidad política nos encontraríamos ante la concurrencia de circunstancias eximentes o dirimentes y cuando simplemente redujera la imputabilidad, ante circunstancias excusantes o aminorantes. Lo cierto es que con anterioridad a CARRARA, CARMIGNANI ya había identificado el concepto de «grado» del delito con la cantidad de intención del sujeto. Desde el momento en que CARRARA defendía que lo que aumentaba la cantidad del delito cambiaba el ente jurídico y la especie del mismo, mientras que el grado presuponía el mantenimiento del título ordinario, el maestro de Pisa al diferenciar entre las circunstancias modificativas agravantes, las atenuantes y las eximentes, acabó señalando que las agravantes especiales no variaban el grado del delito, ni afectaban a la teoría del grado, sino que afectaban directamente a su calidad y/o cantidad, de suerte que venían a suponer un aumento de la «cantidad política» del delito, al expresar la violación de diferentes tipos de delitos o porque reduciendo la potencia de la defensa privada aumentaban el daño mediato; de esta suerte, la concurrencia de tales circunstancias agravantes especiales suponía para CARRARA un cambio del título del delito, lo que se reflejaba de ordinario en la norma con un cambio de nomen iuris, y suponiendo en definitiva una mutación de su especie sin que implicaran, en sentido estricto, una degradación o agravación de la misma. Al contrario de lo que sucedía con las circunstancias agravantes, para CARRARA las circunstancias atenuantes se ubicaban en la teoría del grado, diferenciando entre las relativas a la fuerza moral, y las relativas a la fuerza física. Dentro de las relevantes para la fuerza moral CARRARA diferenciaba entre las relativas a la inteligencia del sujeto y las relativas a la voluntad. Dentro de las relativas a la inteligencia, a su vez diferenciaba entre las causas físicas y psicológicas -como la edad, el sexo, el sueño, la sordomudez o la locura-y las causas morales o ideológicas -como la ignorancia y el error-; y dentro de las relativas a la voluntad significaba la la coacción, el ímpetu de los afectos, y la embriaguez. Dentro de las relevantes para la fuerza física, CARRARA ubicaba los grados de ejecución imperfecta del delito tentativa y frustración- y las formas de participación diferentes a la autoría, como la complicidad. CARRARA criticó de forma especialmente ácida la disciplina que respecto a las circunstancias atenuantes indefinidas se mantenía en Francia, ámbito en el que el Juez disponía de un amplísimo margen de maniobra al amparo de su albedrío, aduciendo que ello era debido, inequívocamente a la confusión entre el grado del delito y el grado de la pena. Vid. MelChionda, A.: Le circostanze del reato..., op. cit., p. I28-I29. CARRARA prestó especial atención también a la comunicabilidad de las circunstancias modificativas de la responsabilidad criminal entre los codelincuentes, y así, en relación con las circunstancias personales concurrentes en uno de los delincuentes que poseían el efecto de «aumentar o disminuir su imputación» las consideraba no comunicables a los restantes partícipes, señalando de este modo que circunstancias como la reincidencia, la cualidad de forastero, $\mathrm{u}$ otras que conllevaban agravio de excusa eran estrictamente personales y no comunicables. Respecto a los casos en los que las cualidades personales influían en el título del delito el caso era complicado según palabras del propio CARRARA -a diferencia del supuesto en el que las cualidades agravantes consistieran en circunstancias materiales del hecho, supuesto en el que reconocía la comunicabilidad a todos los partícipes siempre que fueran conocedores de las mismas y con el límite del exceso en que pudiera incurrir alguno (supuesto de no comunicabilidad)-; para estos supuestos, CARRARA, rechazó de plano acudir a criterios formales para fundamentar la solución y terminó reconociendo la complejidad del asunto al señalar que: «mi mente fluctúa (lo confieso) en esta grave 
Francesco CARRARA, el Maestro de Pisa, desarrolló y perfeccionó el pensamiento trazado por su maestro y preceptor toscano Giovanni CARMIGNANI (I778-I847), y en su Programa del curso de derecho criminal (1859), planteó ya desde un principio la diferenciación entre la teoría de la imputación y la teoría de la pena, señalando que mientras que la teoría de la imputación contempla el delito en relación con el agente y sus relaciones con la ley moral, el libre albedrío y la responsabilidad humana, la teoría de la pena contempla el delito en su vida exterior. Para CARRARA la imputabilidad se funda en el principio del libre albedrío, que acepta sin ambages, y afirma que a pesar de que no puede existir pena mientras no haya imputación, por el contrario puede existir imputación que no vaya seguida de pena; y del mismo modo, aun cuando lo que modifica la imputación debe influir en la pena, ésta también puede modificarse sin que la imputación resulte alterada.

Para CARRARA el delito era la infracción de la ley del Estado, promulgada -lo que era exigido por la seguridad jurídica- para proteger la seguridad de los ciudadanos, resultante de un acto externo del hombre, positivo o negativo, moralmente imputable y políticamente dañoso, y venía a ser no un ente de hecho, material o social, sino un ente jurídico, y ello por cuanto su esencia era la violación de un derecho connatural del hombre, de suerte que el Derecho humano no puede sino ser reflejo del orden natural emanado del Creador. El objeto del delito no era la cosa o el hombre sino el precepto violado. La Ciencia del derecho penal para CARRARA es un orden de razones que emana de la ley moral jurídica y que preexiste a todas las leyes humanas. Para CARRARA el Derecho criminal es complementario de la ley moral jurídica, de suerte que con la prohibición, la viene a confirmar y le da aquella sanción eficaz, que, de otro modo, no tendría en este mundo, mientras que con el procedimiento penal se persigue su observancia práctica. Si el delito es un ente jurídico y no un ente social o de hecho, tan sólo podrán ser considerados delictivos los actos voluntarios y libres que ofenden el derecho ajeno, de suerte que en el delito confluyen dos fuerzas especiales: una voluntad inteligente y libre, y un hecho exterior, lesivo del derecho o peligroso para el mismo.

CARRARA y CARMIGNANI fundamentaban las eximentes precisamente en atención a carencias en el ámbito de la inteligencia (edad, sexo, enfermedad mental, error e ignorancia) o de la voluntad (coacción, ímpetu o embriaguez). Adelantándose incluso a R. Von IHERING quien en 1867 distinguirá dentro de la noción de imputabilidad, la contradicción del acto con el ordenamiento jurídico (antijuridicidad) y el reproche formulado a su autor (culpabilidad), CARRARA diferenciaba ya en su Programa entre la imputación física del hecho al agente, la imputación moral del mismo, en la medida en que el mismo haya respondido a la voluntad de realización del sujeto, y la imputación legal en la medida en que el hecho haya supuesto obrar contra la Ley.

CARRARA, que dejaba en manos del juez y no del legislador la determinación de la concreta fuerza objetiva final de la pena para cada caso -en una suerte de tarea consistente en completar la labor del legislador-, conceptuaba la pena como esencialmente divisible y fraccionable al objeto de poder así responder adecuadamente al diverso grado de la imputación concreta, partiendo de una necesaria proporción entre delito y pena ${ }^{6}$. Al igual

cuestión» Vid. CARrARA, F.: Lezioni sul grado della forza física del delito (conato, complicità), $6^{a}$ ed., dettate nella R. Universitá di Pisa, Lucca, Tip. Giusti, ı870, p. 272 y ss.

${ }^{6}$ Vid. MelchiondA, A.: Le circostanze del reato..., op. cit., p. i28. Para el maestro de Pisa, el juez no podía aplicar el máximo de pena donde no concurrieran circunstancias agravantes ya que de obrar de ese modo estaría actuando de forma no proporcionada y violentando la ley que establece el aumento de pena, dentro de los límites legales, por la concurrencia de circunstancias de agravación, y por ello propuso introducir una regla general tendente a garantizar la proporcionalidad, al objeto de que no se castigara por la medida mínima de la pena en los casos en los que no concurrieran circunstancias aminorantes o atenuantes, y que del mismo modo no se castigara con el máximo de la

Redur 4 / 2006 
que aconteciera con el delito, CARRARA distinguía en la pena entre calidad, cantidad y grado de la misma; y mientras que con la calidad de las penas hacía referencia a la clasificación de éstas y más en concreto al bien que se sacrificaba del reo con la imposición de la pena distinguiendo entre penas capitales, aflictivas, infamantes y pecuniarias-, con el concepto de cantidad se refería a la gravedad del sufrimiento del sujeto con la concreta pena impuesta a cada individual infracción, de suerte que los criterios de calidad y cantidad eran los manejados por el legislador a la hora de diseñar proporcionalmente la tipología de los delitos y la de sus correlativas penas. Por su parte, en el ámbito de la pena, con la teoría del grado se ponían de manifiesto las causas de modificación del castigo que procedían de las condiciones y del fin de la pena, destacando la necesidad de no confundir entre lo que dio en llamar causas extrínsecas, o políticas y las causas intrínsecas o jurídicas; de esta suerte, mientras que unas podían llevar a una simple modificación, o conmutación de la pena, otras podían determinar la suspensión de la misma a pesar del merecimiento de pena.

La legitimidad de la represión penal en CARRARA descansa en que la coacción moral en que consiste la pena, mediante la amenaza, sirve para prevenir la violación de los derechos de los demás y proteger así su esencia; en definitiva, el fundamento del Derecho Penal en CARRARA se aposenta en la tutela jurídica de los derechos ajenos.

Como se sabe, el pensamiento positivista en el ámbito penal se orientó en dos direcciones absolutamente dispares en el estudio del delito: el positivismo criminológico italiano centrado en el delincuente, y el positivismo jurídico alemán que hizo del delito como infracción de la ley penal positiva su centro de atención. La Scuola Positiva centrará su atención en la peligrosidad del criminal como refirió LOMBROSO ${ }^{8}$, o en la «temibilitá» en

pena allí donde no concurrieran circunstancias agravantes. Vid. MelChiondA, A.: Le circostanze del reato..., op. cit., p. I25, nota (I86).

7 Dentro de las causas jurídicas o intrínsecas de modificación de la pena encuadraba aquellos supuestos en que, ya por circunstancias individuales -subdividiendo y distinguiendo dentro de esta tipología entre causas de disminución y causas de aumento de la pena- o ya por un cambio en la voluntad del legislador -supuestos circunscritos y limitados a la entrada en vigor posterior de la norma penal más favorable-, se podía modificar la pena. Dentro de las causas de disminución de la pena se englobaban los supuestos ordinarios en que por la edad senil del sujeto, por su sexo, por su enfermedad o por un eventual concurso de penas, entre otros supuestos, determinaban el surgimiento de una excepcional sensibilidad física del reo, de suerte que la pena ordinaria, o fuerza física objetiva de la pena correspondiente supondría para el mismo un sufrimiento demasiado grave e innecesario; por su parte, dentro de las causas de aumento de la pena tan sólo contemplaba la reincidencia, y ello aún cuando en principio, para CARRARA, la reincidencia no constituía una circunstancia agravante en sentido estricto, no obstante era un remedio para corregir la insuficiencia relativa de la pena ordinaria para estos casos. Vid. MELCHIONDA, A.: Le circostanze del reato..., op. cit., p. I26 ss. En realidad la diferenciación entre causas intrínsecas y causas extrínsecas fue tomada por CARRARA de su maestro CARMIGNANI, quien en su obra Elementi di diritto criminale, Ed. Francesco Sanvito, Milano, I863, p.133 ss., 364 Ss., y de la que ya había una edición en I847-I848, es decir, unos once años antes de publicar CARRARA su Programa, ya había distinguido entre "causas que proceden de la naturaleza intrínseca del delito», «causas que proceden de la naturaleza intrínseca o de la naturaleza moral de la pena» y «causas extrínsecas de mitigación o remisión de las penas». En relación con las «causas que proceden de la naturaleza intrínseca del delito», CARMIGNANI contemplaba en su seno aquellas circunstancias que presentaban una relevancia especifica en relación con el «grado» del delito, basándose generalmente ya en una variación de la cantidad de la intención o de la ejecución; por lo que hace a las «causas que proceden de la naturaleza intrínseca o de la naturaleza moral de la pena», para CARMIGNANI las primeras tenían relación directa con la mayor o menor sensibilidad del reo con respecto a la pena, mientras que las segundas se encontraban relacionadas con el carácter infamante de algunas penas; por último, dentro de las «causas extrínsecas de mitigación o remisión de las penas» CARMIGNANI hacía referencia a determinadas circunstancias como la confesión y otras similares.

${ }^{8}$ La doctrina suele tildar como padre de la Criminología científica moderna, como disciplina autónoma, a E.M.C. LOMBRoso (aunque luego veremos cómo hay quien incluso atribuye tal 
paternidad a otro miembro de esta Escuela, a Rafael Garófalo) autor de «El hombre delincuente», donde describe el prototipo criminal, el delincuente por excelencia al que él llamó «criminal nato» (GARRIDO GUZMÁN, L.: «Concepto y alcance de la Criminología. Evolución Histórica y relaciones con el Derecho Penal», en Criminología y Derecho Penal, VVAA, Ed. Edijus, Zaragoza, I998, p. 25, atribuye la utilización del criminal nato o delincuente nato a LomBroso, sin embargo, sobre la paternidad de la expresión «criminal nato» existen ciertas discrepancias; para HERRERo HERRERO, C.: Criminología (Parte General y Especial), Ed. Dykinson, Madrid, I997, p. 60, la expresión es propia de E. FERRI; en cambio, para MANUEL DE RIVACOBA, delincuente nato es una expresión que se autoatribuyó FERRI, cuando en realidad su paternidad correspondió al frenólogo Mariano Cubí y Soler; Cfr. DE RivacoBA, M.: Elementos de Criminología, Ed. Universidad de Valparaíso, Fac. CC Jurídicas, Económicas y Sociales, Chile, 1982, p. ir6, nota i79; en el mismo sentido se pronuncia CUELLO CALON, para quien -siguiendo a Ramos- la expresión «criminal nato» tendría su paternidad en Cubí y Soler. Para Cerezo (Cerezo Mir, J.: Curso de Derecho Penal Español. Parte General. I. Introducción, Ed. Tecnos, $5^{a}$ Ed., Madrid, I996, reimpresión I997, p. 67), LOMBROSO, al formular en I876 su teoría del delincuente nato «sentó las bases de la Antropología criminab. De Cesare LOMBROSO puede decirse que su principal aportación ha sido su propuesta de aplicar el mismo método científico de las ciencias naturales al estudio de la criminalidad (GARRIDO, V.- STANGELAND , P.- Redondo, S.: Principios de Criminología, Ed. Tirant lo Blanch, Valencia, I999, p. 262), formulando su construcción sobre la base del positivismo de Comte del cuarto decenio del siglo XIX, más el materialismo de Jacobo Moleschott, de quien Lombroso tradujo una de sus obras -si bien sobre esto último existen autores que niegan la influencia del médico holandés sobre Lombroso, como sostiene Giulio Andrea Belloni-; influyéndole también de forma decisiva Ernesto Haeckel y su teoría de la ley biogenética fundamental, así como las construcciones de Prichard con su concepto de locura moral, Carlos Federico Heusinger y su concepto de «degeneración» o del padre de la Anatomía Patológica, Augusto Benedicto Morel (Vid. DE RivacobA, M.: Op. cit., p. 97 a I25); no puede dejarse aquí de reconocer, además, la especial influencia que ejerció sobre LomBroso a lo largo de toda su vida, Paolo Marzolo, quien llegó a ser la persona que lo orientó hacia el estudio de la Medicina; el criminal por naturaleza, según Lombroso es un hombre predestinado al crimen desde su nacimiento y por su propia naturaleza y ello por presentar una serie de anomalías congénitas, que responden a una motivación corporal que hacen del sujeto que las padece un delincuente incorregible; LOMBROSO aprecia la existencia de un mundo intermedio entre el vicio y la locura: el delito; en el análisis de los locos y los delincuentes, al realizar la autopsia en una mañana de diciembre del famoso bandido Vilella, LOMBROso descubre en el mismo una alteración significativa y sin precedentes, en la base del cráneo del mismo: una depresión que se correspondía con una hipertrofia de la eminencia vermicular del cerebelo, que si bien era relativamente frecuente en pájaros y en determinados vertebrados inferiores, no se presentaba en los superiores, salvo como anomalía en determinados embriones a los tres o cuatro meses de gestación; esta alteración fue denominada por LomBRoso foseta occipital media; a partir de aquí comienza Lombroso a construir su teoría sobre la naturaleza anómala del delincuente, insinuando incluso la presencia en éstos de una probable detención del desarrollo del cerebro en el estado fetal; así LOMBROSO, y tras varios artículos publica su primera edición del «Trattato antropológico sperimentale dell'uomo delinquente», que a partir de su segunda edición denominará «L'uomo delinquente in rapporto all'antropologia, alla giurisprudenza a alle discipline carcerarie». Para Lombroso, el delincuente «es un ser atávico (de ahí que HERRERO HERRERO califique la aportación de LOMBROSO como de «Atavismo criminógeno», op. cit., p. 59), análogo al loco moral, de base epiléptica y con un tipo somático y psíquico especial» (DE RIVACOBA, M.: Op. cit., p. IO9). En esta concepción inicial lombrosiana, el delincuente no es en realidad un enajenado, sino un ser primitivo, mas bien parecido a un niño, considerando la criminalidad como una «continuación de la edad infantil, como un estado de infancia prolongada». Sin embargo, para este autor no llega a existir en el delincuente nato ningún «determinismo criminógeno absoluto», sino que tan sólo existe, en el mismo, una fuerte predisposición al delito. Para Lombroso, los niños son «perversos instintivos» que, mediante la educación, es posible corregir (Herrero Herrero, C.: Op. cit., p. 62). LOMBroso se dedicó de forma empírica a comparar los rasgos que presentaban los tipos de delincuente y que les caracterizaba, llegando a realizar una amplia descripción de los rasgos fisonómicos y psicológicos característicos de cada tipo. Para Lombroso el delincuente nato se caracteriza por «ciertos estigmas de degeneración somáticos», manifestándose los mismos en la cara y cabeza, en general, llegando a enumerar más de treinta y cinco malformaciones corporales. Así LOMBRoso se hacía eco de la presencia de menor capacidad craneana que la normal, aspecto viril del cráneo femenino, desarrollo menguado del diámetro frontal, frente estrecha o huida, prominencia de la protuberancia occipital,

Redur 4 / 2006 
palabras de FERRI ${ }^{9}$ y GAROFALO ${ }^{\text {Io }}$, en suma, en el peligro de que el sujeto lleve a cabo otras conductas delictivas. Para la Escuela Positiva esa peligrosidad podía determinarse en

cabello espeso, oscuro o rizado, cejas muy pobladas y juntas; mirada fría y vidriosa en el asesino, y entre los rasgos psicológicos la insensibilidad moral, la precocidad antisocial, vanidad, imprevisión e incorregibilidad (resulta muy interesante la relación que formula DE RIVACOBA, op. cit., p. III a II4, en el que se distinguen rasgos según el tipo de delincuente, señalando que LOMBROSO recibió en este sentido, un fuerte influjo de los fisonomistas, en especial de Jerónimo Cortés). LomBroso incluso dio una opinión sobre lo que el entendía como causa del inferior índice de delincuencia en las mujeres que presentaban los caracteres físicos o psíquicos típicos del delincuente, considerando que la prostitución vendría a ser como un «sustitutivo femenino de la criminalidad en el varón», teoría que no recibió muchos apoyos ni siquiera dentro de los propios positivistas. Las tesis lombrosianas fueron intensamente aplaudidas en el primer Congreso Internacional de Antropología Criminal de Roma, en I885, mientras que en el segundo Congreso de París, en I889 fue objeto de encarnizados ataques que llevaron a LOMBROSO a tal grado de disgusto que se negó en redondo a participar en el tercer Congreso. En realidad, como señala DE RIVACOBA, la tesis defendida inicialmente por LOMBRoso, esto es, la de que la constitución orgánica del sujeto determina su carácter criminal o delincuente, es demasiado simplista y hoy en día se encuentra completamente superada. Ahora bien, no se puede tampoco negar, que determinados conceptos que encontraron su origen en la construcción lombrosiana, han pasado a nosotros, y son aceptados hoy en día, bajo otras denominaciones, como por ejemplo el reconocimiento de las personalidades psicopáticas o perversas en la delincuencia. El fallecimiento de Lombroso no implicó la extinción de sus ideas, sino que, al margen de sus adversarios ya en vida, como KURELLA o NAECKE o en Italia LUCCHINI o el P. GEMELLI, aparece una serie de literatura científica que de algún modo le resucitó como los reputados psiquiatras italianos MoRSELLI, MASSINI o en Inglaterra el Dr. Goring o el Profesor Otón en Estados Unidos. Lombroso no mantuvo una única tipología de delincuente, sino que con posterioridad a aquélla formulación inicial restringió ampliamente la importancia que inicialmente daba al delincuente nato. Así, en una ulterior etapa, LOMBROSO modificó su concepción inicial sobre la presencia de las características psicofísicas en el delincuente y llegó a aceptar que estas características estaban presentes tan sólo en un tercio, aproximadamente, de la totalidad de los delincuentes -entre un 35 y un $40 \%$ del total de las personas que delinquen, según DE RIVACOBA (DE RivACOBA, M.: Op. cit., p. II6 у II7)-, aceptando ya en este ulterior momento, no sólo el influjo de elementos biológicos, sino la presencia de factores físicos, sociales y económicos como causas del crimen, en especial para los delincuentes ocasionales (Vid. GARRIDO GUZMÁN, L.: Op. cit., p. 25). De esta forma LOMBrOSO dio entrada, junto con el delincuente nato, y dentro de la tipología delicuencial a otras como el loco moral, el delincuente epiléptico, el delincuente loco, el delincuente ocasional, la delincuencia femenina o la delincuencia política (GARCíA PABlos DE MolinA, A.: Tratado de Criminología, Ed. Tirant lo Blanch, Valencia, I999, p. 38 i a 390). Según opina la generalidad de la doctrina, la verdadera importancia de LOMBROSO no hay que buscarla en sus opiniones sobre el delincuente nato, sino en el hecho de que basó sus afirmaciones en la investigación empírica a través del análisis de muchos delincuentes convictos, principalmente homicidas, como base de sus tesis. En este sentido, y a pesar de que muchas de sus tesis han sido ampliamente superaras con posterioridad (incluso se podría decir que las principales críticas que contra el mismo se han vertido atacan sus postulados básicos, como la escasa importancia que sobre todo en un principio dio a los factores sociales y ambientales, la negación de la existencia de supuestos rasgos degenerativos en los delincuentes o que los rasgos anatómicos resaltados por LOMBROSO los tienen la mayoría de las personas careciendo por tanto del efecto criminógeno pretendido (-Cfr. GARCíA PABlos DE MolinA, A.: Op. cit., p. 393 a 397-) no se puede dejar de reconocer el gran impulso que supuso LOMBROSO en la utilización del método experimental para el estudio del hombre, así como su optimismo científico y su amor por la docencia, inscribiendo en el acervo de las ciencias, «una nueva, de porvenir magnífico: la Criminología» (DE RIVACOBA, M.: Op. cit., p. IO5; GARRIDO GUZMÁN, L.: Op. cit., p. 25). En este sentido, el gran mérito de Lombroso es «el haber llamado la atención sobre el protagonismo del hombre delincuente en el suceso criminal, del hombre real, concreto, histórico. Que no existe el crimen, sino el criminal. Y sobre la necesidad de aproximarse al estudio de ese hombre con un método científico, empírico, basado en el análisis y observación del mismo, libre de dogmas, aprioris o prejuicios» (GARCÍA PABLOS DE MOLINA, A.: Op. cit., p. 393).

9 Dentro de la Scuola positiva habría que incardinar también al brillante profesor de Derecho penal, abogado y orador, discípulo de Cesare LOMBROSO, Enrico FERRI. Este, padre de la Sociología criminal como realidad científica (GonZÁlEz RAdio, V.: Sociología Criminal, Ed. Tórculo, Santiago

Redur 4 / 2006 
de Compostela, I997, p.4I), fue quien precisamente acuñó dicha expresión. FERRI publicó en I896 su Sociología Criminal (aunque sobre la fecha de la publicación existen diferentes opiniones en la doctrina: es curioso que GARRIDO GUZMÁN, op. cit., p. 25 señala que fue en I896, en tanto que MANUEL DE RIVACOBA, op. cit., p. I24, señala que la expresión Sociología criminal la empleó ya en I879 en la Rivista penale, en un artículo, y luego, posteriormente en I88I en un libro; por su parte, HERRERO HERRERO, op. cit., p. 63 considera que la obra «Sociología criminale» apareció en i88o; por su parte GARRIDO-STANGELAND-REDONDO, sostienen que la Sociología criminal de FERRI se publicó en i878, «tan sólo dos años después de la primera edición del libro de Lombroso») en la que inicia un proceso de diferenciación de su maestro LOMBRoso, distinguiendo varios grupos de delincuentes diferenciados de los formulados por aquél, además de atribuir -frente a su maestro- una mayor importancia en la etiología de la delincuencia a los factores sociales, económicos y políticos. Resulta curiosa la anécdota que refiere Rodríguez MANZANERA (Rodríguez MANZANERA, L.: «Criminología», Ed. Porrúa, $7^{a}$ ed., México, I99I, p.218) cuando señala que habiéndole remitido su tesis doctoral FERRI a LOMBROSO, éste comunicó a su común amigo Turati que en su opinión, FeRRI adolecía de ser poco positivista, lo que enfadó sumamente a FERRI, respondiéndole a TURATI «¿Acaso pretende LOMBRoso que yo, jurisconsulto, vaya a medir cabezas de delincuentes para ser bastante positivista.3. FERRI diferencia al delincuente nato, al loco o alienado, al pasional, al ocasional, al habitual y al pseudodelincuente o delincuente involuntario (GARCíA PABLOS DE MolinA, A.: Op. cit., p. 409). Al mismo tiempo negaba el libre albedrío, considerándolo una mera ilusión subjetiva, y ello por cuanto el hombre se halla sometido a las leyes de la naturaleza, a la causalidad, de tal modo que son muy diversas las causas que determinan su comportamiento, siendo importante también considerar su eventual combinación como causa del resultado final (GARCíA PABLOS DE MOLINA, A.: Op. cit., p. 404 a 4 IO $)$. FERRI considera que la pena tiene como finalidad, no tanto el castigo del delincuente como la defensa de la sociedad, presentando un sociologismo moderado, por cuanto considera que el delito deriva de una anomalía biológica, física y social, llegando a formular la teoría de los sustitutivos penales al considerar que las penas son incapaces de neutralizar otros factores que no sean los psicológicos en la comisión de los delitos, considerando que si bien las penas son imprescindibles, son insuficientes, siendo precio un Código preventivo que resultará mucho más eficaz que las penas. No obstante, la concepción de FERRI sobre la reacción social defensiva frente al delito va a ser diversa, dependiendo del tipo de delincuente ante el que nos encontremos. Así, partiendo de que todo individuo que ejecuta un hecho debe ser sancionado de acuerdo con su peligrosidad, llega a proponer penas eliminatorias para los delincuentes natos y penas reparadoras o represivas para los ocasionales (en este sentido, GARCíA PABlos DE MolinA, A.: Op. cit., p. 405, señala que «en cuanto a la pena capital, tal vez sea demasiado generosa la doctrina cuando considera a FERRI claro partidario de las tesis abolicionistas, a diferencia de la postura contraria de GAROFALO partidario de la pena de muertes). FERRI concibe la Sociología criminal en un sentido enciclopédico, comprensivo de la Antropología, la Psicología y la Estadística criminales, el Derecho penal y las disciplinas penitenciarias. Acusó una temprana influencia de la Escuela Sociológica francesa, sin renegar jamás del influjo que recibió de LOMBRoso en orden a la importancia de la constitución antropológica. De hecho, CEREZo MiR (CEREZo MiR, J.: Curso ... I. Introducción, p. 68) considera que la Sociología criminal se inicia por la Escuela Sociológica francesa de Lyon, habiendo sido sin embargo FERRI quien le dio gran impulso y divulgación. La Escuela socio-criminológico francesa de Lyon parte de unos postulados opuestos a la doctrina de Lombroso. Cerezo Mir, J.: Curso ... I. Introducción, p.67-68, señala como principales representantes de esta Escuela a A. LACASSAGNE (I843-I924) y Gabriel TARDE (I843-I904), aunque -como ya vimos- considera que FERRI fue su gran impulsor, logrando su divulgación. Por su parte, GARCía PABlos DE Molina sitúa como precursores de esta Escuela a LAMARCK, HILAIRE o PASTEUR, señalando que la mayoría de los autores adscritos a la Escuela Socio-criminológica francesa o escuela del medio, han sido médicos, y no juristas. LACASSAGNE, médico y profesor de Medicina Legal en Lyon, es considerado por GARCíA PABlos DE MOlinA, A.: Op. cit., p. 429-430, el ideólogo de esta Escuela. LACASSAGNE distinguía dos tipos de factores con influencia en el delito: los individuales -que tenían un peso muy escaso- y los sociales -que serían los decisivos-. Este autor, aunque reconoce que en los delincuentes suelen evidenciarse mayores anomalías psicofísicas que en los no delincuentes, considera que ese dato no es el explicativo del delito, sino que como mucho puede explicar simplemente una predisposición, pero el caldo de cultivo, sigue siendo la sociedad. LACASSAGNE, inspirándose en QUÉTELET, partía de considerar al delito como delincuencia despersonalizada, de tal forma que el delito para este autor, no era un fenómeno individual sino que en realidad existía un fenómeno socio-criminal, pero no propiamente criminales individualizados. El jurista, psicólogo y sociólogo francés Gabriel TARDE, profesó, según García PABloS DE Molina, A.: Op. cit., p. 434, una teoría psicosocial de la

Redur 4 / 2006 
criminalidad. TARDE formuló la teoría del delincuente profesional que posteriormente será desarrollada por SUTHERLAND, así como las famosas «leyes de la imitación», a tenor de las cuales las personas observan e imitan los comportamientos de los que les rodean -Vid. también GARRIDO, VSTANGELAND, P-REDONDO, S.: Op. cit., p. 2I3- a partir de lo cuál dará su explicación de porqué en las ciudades existe más delincuencia que en la zona rural: por existir más modelos a imitar, confiriendo también importancia al hecho de que las modernas sociedades industriales suponen una ruptura con las normas tradicionales. TARDE concebía la criminalidad desde postulados colectivistas-marxistas. El criminal para TARDE era una víctima más de la sociedad desordenada que era, realmente, la que impulsaba al hombre hacia el delito, Vid. en este sentido a Herrero Herrero, C.: Op. cit., p. 63-64. TARDE formula sus proposiciones desde una postura frontalmente beligerante respecto del positivismo antropológico de LOMBROSO, de tal suerte que para él, el delito no es un fenómeno antropológico, sino social, gobernado por la imitación, girando toda su filosofía alrededor de tres conceptos: invención, imitación y oposición. Señala GARRIDO GUZMÁN, Op. cit., p. 26-27, que en I882, LACASSAGNE y TARDE vinieron a proclamar que «Cada sociedad tiene los criminales que se merece», confiriendo primacía al factor social sobre el individual en la explicación del surgimiento del delito, comparando al criminal con el microbio, que permanece inofensivo hasta que encuentra el caldo de cultivo adecuado que le permite cometer crímenes, e invocando a TARDE señala «Todo el mundo es culpable excepto el criminal», como este autor había concluido en su obra "La Criminalité comparée» en I898. GARRIDO ubica dentro de esta escuela al declarado enemigo de TARDE, Emile DURKHEIM (I858-I9I7), quien en I895 se vendrá a ocupar del análisis estadístico criminal, así como de la explicación del delito por la imitación, destacando como y hasta qué punto delito y criminalidad constituyen una parte integrante de todo la sociedad sana, considerando ya que el delincuente no es una persona distinta sustancial o cualitativamente. Para GARRIDO-STANGELAND-REDONDO, Op. cit., p.2I3, DURKHEIM sería el iniciador de la llamada Escuela funcionalista, centrándose en el análisis de la influencia de los valores sobre la conducta social, considerando que el sometimiento de los sujetos al grupo se debe, no tanto al temor, como a la existencia de un sistema de valores primarios. Pero sobre estas cuestiones se volverá cuando analicemos la corriente funcionalista, como orientación base del funcionalismo penal contemporáneo. Para FERRI (DE RIVACOBA, M.: Op. cit., p. I23 a I25): «El medio social da la forma al delito, que tiene su base en el factor biológico». En realidad, y pese a su evolución innegable, LOMBROSO no dejó nunca de ser un antropólogo, en tanto que FERRI recogió la doctrina de su maestro, pero la enriqueció con el estudio acerca del influjo del ambiente sobre el delito (Vid. De RivacoBA, M.: Op. cit., p. I23).

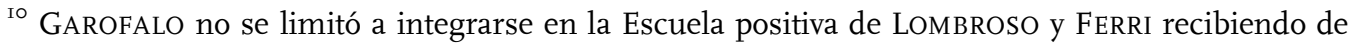
la misma una postura que luego el mismo pudiera defender, sino que aportó personalmente elementos muy interesantes a la conformación de la esencia de la propia escuela. Para algunos autores Vid. GARRIDO-STANGELAND-REDONDO, Op. cit., p. 266, GAROFAlO es el padre de la Criminología, y ello al considerar que sus discípulos al analizar las ideas de su maestro, plasmadas en más de 600 obras iniciaron diferentes perspectivas de estudio considerando los factores socioculturales, los psicológicos, los biológicos y los genéticos en la explicación del fenómeno delictivo. GAROFALO, perteneciente a la carrera judicial italiana, y profesor de la Escuela de Derecho penal de Nápoles, llegó a las más altas instancias (Presidente de Cassazione) de la carrera judicial, tomando una postura personal muy peculiar incluso antes de ingresar en la Scuola, pudiéndose decir que contribuyó a sentar las bases de la misma así como su orientación jurídica, introduciendo conceptos como «peligrosidad» y «prevención especial y general», ya en I877, Vid. RODRÍGUEZ MANZANERA,, L.: Op. cit., p. 22I. En relación con el concepto de peligrosidad, GAROFALO concentra en él sus consideraciones en relación a las anomalías psíquicas de los delincuentes incorregibles, sobre todo en su dimensión moral, Vid. Herrero Herrero, C.: Op. cit., p. 62. Garofalo, en su obra «Criminología» (I885) expone por primera vez la teoría del delito bajo la denominación «Criminología», Vid. GARrido GuZMÁn, L.: Op.cit., p. 26. Con esta obra, como señala Cerezo Mir, J.: Curso... I, Introducción, 68 y nota (40), el término Criminología-que había sido acuñado por el antropólogo francés Toppinard (I830-I9II) - se generalizó. En esta obra, GAROFALo llegó a crear un llamado «delito naturah», independiente de las normas y desligado del lugar y del tiempo. Para GAROFALO resultaba necesaria la definición del delito, y ello por cuanto el positivismo criminológico se había centrado hasta ese momento exclusivamente en el delincuente, pero no en el delito. Sin embargo, para GAROFALO era precisa una definición de delito «con independencia de las pautas legales». Y así es como el mismo define el «delito natural», una noción de crimen estrictamente criminológica y autónoma, Vid. GARCíA PABlos DE MolinA, A.: Op. cit., p. 4I2. En realidad, como señala RODRÍGUEZ MANZANERA, L.: Op. cit., p. 22I, remitiéndose a GÓMEZ GRILLO, «Si Lombroso concibió la Criminología como Antropología Criminal y FERRI como Sociología Criminal, Garófalo 
atención a la gravedad, motivos y circunstancias modificativas de la responsabilidad criminal, y además tomando en especial consideración la personalidad del delincuente en base a sus condiciones individuales, familiares y sociales. Los positivistas italianos no se centraron en el delito como realidad jurídica, sino en el mismo como acción humana proveniente o resultado de determinadas circunstancias físico-sociales de un determinado sujeto delincuente, centrando pues su atención no sólo en la conducta, sino en el hombre mismo, en las causas de su comportamiento y en el problema social que el delito suponía. De este modo la aplicación de la pena toma su fundamento en la peligrosidad del sujeto delincuente, línea de pensamiento que tendrá evidentes repercusiones en el Derecho penal con la introducción de la doble vía en el sistema de sanciones, en el que harán acto de presencia las medidas de seguridad, en un buen número de legislaciones penales positivas (el positivismo criminológico italiano ha tenido especial influencia en el pensamiento penal español en el llamado Correccionalismo, y en autores como SALILLAS, CONCEPCIÓN ARENAL o DORADO MONTERo), y al mismo tiempo se sostendrá -dado el carácter del problema social que el delito suponía-, que el Estado debe intervenir para solucionar el problema del delito de una forma preventiva, actuando sobre los factores exógenos y endógenos originadores del mismo, con el objeto no tanto de retribuir la infracción, sino de defender a la sociedad misma evitando el delito ${ }^{\text {II }}$.

no va a intentar ni uno ni otro fin. Su misión consistirá en terminar de enhebrar con fríos raciocinios éticos y sociológicos, con ajustada lógica jurídica, el enjambre conceptual del novísimo testimonio científico». Sin embargo el intento de GAROFALO de sustituir el estudio del delito con el tradicional método jurídico creó muchos opositores a su planteamiento, sin que podamos dejar de reconocer que el mismo surgió con grandes ambiciones. Como señala GARCÍA PABLOS DE MolinA, A.: Op. cit., p. 4II el mérito de RAFFAELE GAROFALO, hay que encontrarlo en la «brillante y rigurosa exposición sistemática del credo de la Scuola positiva», y en especial en el énfasis de qué éste fuera algo más que un simple credo doctrinario, intentando que el mismo fuera asumido por el ordenamiento jurídico, por las instituciones y que imbuyera el tejido social a través de la praxis diaria de los tribunales. GAROFALO supuso, en esencia un intento por sistematizar jurídicamente las doctrinas criminológicas del positivismo. Si bien tanto FERRI como GAROFALO, en un primer momento se mostraron «ortodoxos discípulos» de LOMBRoso, en un segundo momento variaron o complementaron, de alguna forma «el mensaje lombrosiano» (HERRERO HERRERO, C.: Op. cit., p. 62). En realidad, GAROFAlO (RODRÍGUEZ MANZANERA, L.: Op. cit., p. 22I) vino a suponer una postura de equilibrio entre LOMBROSO y FERRI, si bien debe señalarse que determinadas posturas de este autor, y en algunos aspectos, llegó incluso a separarse de sus colegas de escuela, en especial en cuanto resultó ferviente defensor de la pena de muerte y su no aceptación del determinismo absoluto. En líneas generales podría señalarse que serían puntos de alejamiento respecto a las posturas de LOMBROSO y FERRI el determinismo moderado que propugnó GAROFALO, su carácter extremadamente conservador, el resultar partidario de la pena capital -con la finalidad de defender a la sociedad de los mismos-, el no compartir la teoría de la criminalidad antropológica de LOMBROSO ni el sociologicismo de FERRI, así como el defender el principio de la prevención especial como fundamento del castigo. Por otra parte, puntos de coincidencia con LOMBROSO y FERRI serían tanto el compartir el método empírico-inductivo como el partir de un reconocimiento de la superioridad de la sociedad sobre el individuo, en sus formulaciones (GARCíA PABlos DE MOLINA, A.: Op. cit., p. 4II y 4I2). La tesis principal de GAROFALO podría sintetizarse en que consideraba que el origen de la delincuencia había que buscarlo en una deficiencia psíquica o moral del sujeto, que tenía carácter hereditario, provocando una falta de desarrollo de sentimientos altruistas y una incapacidad de adaptación a la vida social (Cfr. GARRIDO, V.-STANGElAnd, P.- REDONDO, S.: Op. cit., p. 266). El delincuente se caracterizaba así por una «anomalía moral, por la ausencia o desviación del sentido moral y con frecuencia, de acuerdo con la tesis lombrosiana, por sus anomalías somáticas». GAROFALO realizó una tipología criminal diferente de las que habían sido formuladas por LOMBROSO y FERRI, distinguiendo cuatro clases de delincuentes: asesinos, violentos, ladrones y criminales lascivos, considerando para ello el grado de carencia que exhibían en los sentimientos morales altruistas de probidad y piedad (GARCíA PABlos DE MOLINA, A.: Op. cit., p. 4I5).

II Posteriormente, ya en el siglo XX surgirá el movimiento conocido como «nueva Defensa Sociab), corriente que se desarrollará bajo las humanistas formulaciones de ANCEL PRINS y GRAMATICA, y que hundirá sus raíces en estas concepciones del positivismo criminológico italiano,

Redur 4 / 2006 
En la Terza Scuola, Alimena sostiene que el fundamento de las circunstancias debe encontrarse tanto en la necesidad de graduar el delito como en la de atender al delincuente, diferenciando entre atenuantes inherentes a la persona del reo, personales o subjetivas y atenuantes nacidas del delito, reales $u$ objetivas, mientras que las agravantes, para ALIMENA sólo son reales u objetivas.

En el movimiento de Defensa Social, con GramaticA, se produce la introducción del concepto subjetivo de antisocialidad, de manera que las circunstancias, para los autores adscritos a este movimiento, modifican la antisocialidad, graduándola en más o en menos, pero desde una perspectiva individual o subjetiva ${ }^{\mathrm{I} 2}$.

II. Caracteres generales del modelo italiano actual de circunstancias modificativas de la responsabilidad criminal.

Hoy podemos decir sin temor a equivocarnos, que el sistema italiano de las circunstancias del delito es el más completo de los actuales ${ }^{\mathrm{I3}}$, pudiéndose afirmar aquí, a diferencia de lo que sucede con el tratamiento dogmático que en España se dispensó tradicionalmente a esta materia, que el desarrollo de la teoría general de las circunstancias en Italia ha alcanzado un elevado grado de desarrollo, habiendo dado lugar a continuas reformas legislativas en la materia ${ }^{\mathrm{I}}$, y habiendo tenido lugar en este país numerosas construcciones dogmáticas, como la del «delito circunstanciado» ${ }^{\text {I5 }}$ en oposición al delito

con la atención puesta, no ya en el castigo, sino en la defensa de la sociedad, concepción que ha tenido importantes repercusiones en la Política Criminal.

${ }^{\text {I2 }}$ Vid. Alonso Álamo, M.: El sistema de las circunstancias del delito. Estudio general. Tesis doctoral, Universidad de Valladolid, Facultad de Derecho, I98I.

${ }^{13}$ GonZÁlez CusSAC, J.L.: Teoría general...., op. cit., p. 45, llega a pronunciarse en el sentido de que: «...puede afirmarse, sin ningún género de dudas, que la doctrina italiana es la más rica y fructífera de cuantas existen en el panorama internacional, y su ordenamiento positivo, en esta materia, el más completo y complejo de todos».

${ }^{\mathrm{I} 4}$ Entre las más próximas, debe destacarse la reforma del artículo 59 del Codice Penale operada por la Ley número I9 de 7 de febrero de I990, respondiendo al clamor de la doctrina italiana contra la reminiscencia que la redacción anterior de dicho precepto traía al viejo principio de «versari in re illicita», habiéndose sostenido por la doctrina, prácticamente de forma unánime, que la anterior redacción del citado precepto, había instaurado en relación con las agravantes, la responsabilidad objetiva. En efecto, el citado artículo 59, con anterioridad a la mencionada reforma establecía en su párrafo $\mathrm{I}^{\circ}$ : «Salvo que la ley lo disponga de otra manera, las circunstancias que agravan, atenúan o excluyen la pena, serán apreciadas, respectivamente, en contra o a favor del agente, aunque no las conozca o por error las haya creído inexistentes». Del mismo modo, el párrafo $2^{\circ}$ señalaba: «Si el agente creyere por error que existen circunstancias agravantes, o atenuantes, éstas no serán apreciadas ni en contra ni a favor suyo». Tras la reforma operada por la referida Ley de 7 de febrero de I990, se ha reorientado el precepto al principio de culpabilidad, abandonando los criterios puramente objetivos establecidos con anterioridad.

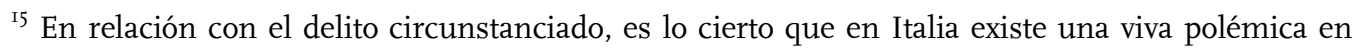
relación con esta cuestión. Así, el delito circunstanciado viene a ser el delito simple al que se añade la concurrencia de determinadas circunstancias comunes, plateándose entonces la controversia dogmática de si al aparecer las circunstancias comunes unidas al delito simple podemos estar o no ante una nueva estructura normativa autónoma. En líneas generales podemos decir que sobre esta cuestión existen casi tantas posturas como autores, si bien habría que diferenciar dos grandes orientaciones situadas en ambos polos de la controversia dentro de los cuales, se ubicarían las posturas intermedias, que cuantitativamente, son las mayoría. Los polos de la controversia serían los correspondientes a la postura minoritaria, mantenida por quienes sostienen que al aparecer el delito circunstanciado -por la aparición de determinadas circunstancias comunes junto con el delito

Redur 4 / 2006 
simple o las polémicas suscitadas en orden a la posibilidad de compensar las circunstancias especiales con las generales.

Con todo, el modelo italiano es muy similar al modelo español. Así, junto con un catálogo de circunstancias generales en su Parte General, (artículos $61^{16}, 62^{17}$ y 62 bis $^{18}$ del Codice Penale), contempla diversas circunstancias también en la Parte

simple- automáticamente aparecería una nueva figura diferente y autónoma del delito simple, y en el otro extremo de la polémica, la postura, con más seguidores que aquella, de quienes sostienen que el delito circunstanciado vendría conformado por el delito simple (que sería el género) al que se añadirían determinadas circunstancias comunes de carácter accidental, dando lugar al delito circunstanciado (especie), de suerte que las circunstancias concurrentes, carentes de autonomía propia, vendrían a ser simples elementos de carácter accidental capaces tan sólo de modificar la gravedad de la infracción, pero sin dar lugar, en absoluto a una nueva estructura normativa autónoma. Además, el Codice Penale contempla en el art. 69 la compensación de estas circunstancias especiales con las generales, situación que no se produce en España.

i6 En este precepto se recogen las circunstancias agravantes «comunes o generales» de la siguiente forma: Art. 6I - Circostanze aggravanti comuni. Aggravano il reato, quando non ne sono elementi costitutivi o circostanze aggravanti speciali, le circostanze seguenti: I) l'avere agito per motivi abbietti o futili; 2) l'aver commesso il reato per eseguirne od occultarne un altro, ovvero per conseguire o assicurare a se o ad altri il prodotto o il profitto o il prezzo ovvero la impunità di un altro reato; 3) l'avere, nei delitti colposi, agito nonostante la previsione dell'evento; 4) l'avere adoperato sevizie, o l'aver agito con crudeltà verso le persone; 5) l'avere profittato di circostanze di tempo, di luogo o di persona tali da ostacolare la pubblica o privata difesa; 6) l'avere il colpevole commesso il reato durante il tempo, in cui si è sottratto volontariamente alla esecuzione di un mandato o di un ordine di arresto o di cattura o di carcerazione, spedito per un precedente reato; 7) l'avere, nei delitti contro il patrimonio, o che comunque offendono il patrimonio, ovvero nei delitti determinati da motivi di lucro, cagionato alla persona offesa dal reato un danno patrimoniale di rilevante gravità; 8) l'avere aggravato o tentato di aggravare le conseguenze del delitto commesso; 9) l'avere commesso il fatto con abuso dei poteri, o con violazione dei doveri inerenti a una pubblica funzione o a un pubblico servizio, ovvero alla qualità di ministro di un culto; Io) l'avere commesso il fatto contro un pubblico ufficiale o una persona incaricata di un pubblico servizio, o rivestita della qualità di ministro del culto cattolico o di un culto ammesso nello Stato, ovvero contro un agente diplomatico o consolare di uno Stato estero, nell'atto o a causa dell'adempimento delle funzioni o del servizio; II) l'avere commesso il fatto con abuso di autorità o di relazioni domestiche, ovvero con abuso di relazioni d'ufficio, di prestazione di opera, di coabitazione, o di ospitalità.

I7 En este precepto se recogen las circunstancias atenuantes «comunes o generales» de la siguiente forma: Art. 62 - Circostanze attenuanti comuni: Attenuano il reato, quando non ne sono elementi costitutivi o circostanze attenuanti speciali, le circostanze seguenti: I) l'avere agito per motivi di particolare valore morale o sociale; 2) l'aver agito in stato di ira, determinato da un fatto ingiusto altrui; 3) l'avere agito per suggestione di una folla in tumulto, quando non si tratta di riunioni o assembramenti vietati dalla legge o dall'Autorità, e il colpevole non è delinquente o contravventore abituale o professionale, o delinquente per tendenza; 4) l'avere, nei delitti contro il patrimonio, o che comunque offendono il patrimonio, cagionato alla persona offesa dal reato un danno patrimoniale di speciale tenuità, ovvero, nei delitti determinati da motivi di lucro, l'avere agito per conseguire o l'avere comunque conseguito un lucro di speciale tenuità, quando anche l'evento dannoso o pericoloso sia di speciale tenuità ; 5) l'essere concorso a determinare l'evento, insieme con l'azione o l'omissione del colpevole, il fatto doloso della persona offesa; 6) l'avere, prima del giudizio, riparato interamente il danno, mediante risarcimento di esso, e, quando sia possibile, mediante le restituzioni; o l'essersi, prima del giudizio e fuori del caso preveduto nell'ultimo capoverso dell'articolo 56 , adoperato spontaneamente ed efficacemente per elidere o attenuare le conseguenze dannose o pericolose del reato.

${ }^{\text {I8 }}$ En este precepto introducido por Decreto ley de I4 de septiembre de I944, se contemplan las llamadas circunstancias «atenuantes genéricas», que vienen a responder, de algún modo y con ciertas reservas, como señala GonZÁLEZ CUSSAC, J.L. Teoría general...., op. cit., p. 42, a nuestra atenuante de análoga significación del art. 21.6ª . En el mismo sentido de considerar que se trata de

Redur 4 / 2006 
Especial, junto con unas reglas generales de aplicación de la pena en la Parte General (art. 59 y siguientes), de las que destaca el minucioso tratamiento del concurso, compatibilidad, aplicación y eficacia de las mismas contenido en los artículos 63 a 69 del Codice.

Al margen de las circunstancias en sentido estricto, en el Codice Penale se recogen también diversos criterios orientativos del arbitrio judicial para los supuestos en que no concurran circunstancias, en el artículo $133^{\text {I9 }}$; estos criterios son definidos por la doctrina como «circunstancias indefinidas o innominadas», si bien, como señala ALONSO ALAMO ${ }^{2 \circ}$, éstas no pueden ser consideradas, técnicamente, circunstancias, ya que los mismos entran en juego, precisamente, cuando faltan las circunstancias, de manera análoga a lo que sucede con el parágrafo 46 del StGB.

Antes de comenzar a desgranar la casuística circunstancial vigente en el Derecho penal italiano actual, es preciso advertir de antemano la existencia de ciertas peculiaridades del sistema que exigen una previa clarificación terminológica a fin de evitar confusiones con el modelo español de circunstancias modificativas de la responsabilidad criminal. Así, en el modelo italiano de circunstancias se diferencia entre circunstancias de apreciación obligatoria, cuya apreciación deviene obligada para el juzgador en cuanto se constate la presencia de sus presupuestos, y circunstancias de apreciación discrecional en cuanto el juzgador dispone de un cierto margen de discrecionalidad para su apreciación o no, como sucede con las denominadas circunstancias atenuantes genéricas ${ }^{21}$; del mismo modo se

las únicas circunstancias genéricas en el Derecho italiano, Alonso ÁlAmo, M.: El sistema..., op. cit., p. I63. Disponía el artículo 62 bis del Codice antes de la última reforma operada en el año 2005 : Attenuanti generiche. Il giudice, indipendentemente dalle circostanze prevedute nell'art. 62, può prendere in considerazione altre circostanze diverse, qualora le ritenga tali da giustificare una diminuzione della pena. Esse sono considerate, in ogni caso, ai fini della applicazione di questo capo, come una sola circostanza, la quale può anche concorrere con una o più delle circostanze indicate nel predetto articolo 62. Tras la reforma operada por la Ley de 5 de dicembre 2005, n. 25I, de modificación del Código penal, entre otras, de la materia de atenuantes genéricas, reincidencia y juicio de comparación publicada en la Gazzetta Ufficiale n. 285 del 7 dicembre 2005 y en vigor desde el día siguiente a su publicación, se añadió al precepto que: «Ai fini dell'applicazione del primo comma non si tiene conto dei criteri di cui all'articolo 133, primo comma, numero 3), e secondo comma, nei casi previsti dall'articolo 99, quarto comma, in relazione ai delitti previsti dall'articolo 407, comma 2, lettera a), del codice di procedura penale, nel caso in cui siano puniti con la pena della reclusione non inferiore nel minimo a cinque anni».

I9 El artículo I32 del Codice se regula el poder discrecional del juez en la aplicación de la pena y sus limites, señalando que: «Potere discrezionale del giudice nell'applicazione della pena: limiti. Nei limiti fissati dalla legge, il giudice applica la pena discrezionalmente; esso deve indicare i motivi che giustificano l'uso di tale potere discrezionale. Nell'aumento o nella diminuzione della pena non si possono oltrepassare $i$ limiti stabiliti per ciascuna specie di pena, salvi i casi espressamente determinati dalla legge». A continuación, el art. I33 dispone, en relación con la gravedad del delito que: «Nell'esercizio del potere discrezionale indicato nell'articolo precedente, il giudice deve tenere conto della gravità del reato, desunta: I) dalla natura, dalla specie, dai mezzi, dall'oggetto, dal tempo, dal luogo e da ogni altra modalità dell'azione; 2) dalla gravità del danno o del pericolo cagionato alla persona offesa dal reato; 3) dalla intensità del dolo o dal grado della colpa. Il giudice deve tener conto, altresì, della capacità a delinquere del colpevole, desunta: I) dai motivi a delinquere e dal carattere del reo; 2) dai precedenti penali e giudiziari e, in genere, dalla condotta e dalla vita del reo, antecedenti al reato; 3) dalla condotta contemporanea o susseguente al reato; 4) delle condizioni di vita individuale, familiare e sociale del reo».

${ }^{20}$ Alonso Álamo, M.: El sistema..., op. cit., p. I62 y ss.

${ }^{21}$ En el sistema italiano las circunstancias indefinidas o innominadas se caracterizan por encontrarse ausente, respecto a las mismas, una taxativa indicación de sus elementos estructurales (Vid. BetTiol, G.: Diritto penale, Parte Generale, II ${ }^{\mathrm{a}}$ ed., Ed. CEDAM, Padova, i982, p. 524), y al 
hace preciso diferenciar entre las denominadas circunstancias comunes o generales y las circunstancias especiales, de suerte que deben considerarse circunstancias comunes o generales las circunstancias que se pueden verificar en un número indeterminado de delitos (son las previstas en los arts. 61, 62, 62 bis y en los art. II2 y II4 del código para el concurso de personas), mientras que las especiales son aquellas que la ley prevé para un determinado delito o para un grupo circunscrito de delitos, encontrándose previstas en la Parte Especial del Código y en las leyes especiales ${ }^{22}$.

Por otra parte, y conforme al art. 63 del Codice penale, habría que diferenciar entre circunstancias que producen un efecto ordinario en la pena y las circunstancias determinantes de un efecto especial en la misma, considerándose a estos efectos como éstas últimas a aquellas que implican un aumento o disminución de la pena superior a un tercio de ésta ${ }^{23}$.

\section{Las circunstancias agravantes comunes o generales.}

Conforme al art. 6I del Codice penale, son circunstancias agravantes comunes o generales el haber actuado el sujeto por motivos abyectos o fútiles ${ }^{24}$; el haber perpetrado el delito para ejecutar $u$ ocultar otro, o para lograr, garantizarse o asegurarse a uno mismo, o a otros, el producto, el provecho, el precio o la impunidad de otro delito ${ }^{25}$; el haber actuado en los delitos culposos a pesar de la previsión del evento ${ }^{26}$; el haber empleado sevicias, o el haber actuado con crueldad hacia las personas ${ }^{27}$; el haberse beneficiado de circunstancias de

mismo tiempo por la remisión al poder de la discrecionalidad del juzgador en cuanto a su apreciación. Estas circunstancias reciben por la doctrina diferentes calificativos, como indefinidas, innominadas, arbitrarias, libres o discrecionales. Vid. BRICCOLA, F.: Scritti di diritto penale, a cura di Canestrari e Melchionda, vol. I, Ed. Giuffrè, Milano, I997, p. 39, 3I9; RomAno, M.: Commentario sistematico del codice penale, V. I, $2^{\text {a }}$ ed. ren. y amp., Ed. Giuffré, Milano, I995, p. 600. A este respecto, NUVOLONE señala que existen circunstancias cuya estructura y esencia aparecen indicados taxativamente por la ley en todos sus elementos, como sucede con las circunstancias previstas en los arts. 6r y 62 del Codice, pero al mismo tiempo existen circunstancias cuya configurabilidad se remite genéricamente al poder discrecional del juez, que es precisamente lo que acontece con el art. 62 bis del Codice, situación que lleva a NUVOLONE a diferenciar así entre circunstancias típicas y circunstancias genéricas; y al mismo tiempo, y analizando el problema desde la perspectiva o punto de vista de las facultades del juzgador, diferencia entre circunstancias obligatorias y circunstancias discrecionales. Vid. Nuvolone, P.: Il Sistema del diritto penale, $2^{\text {a }}$ ed., Ed. CEDAM, Padova, I982, p. 4 .

${ }^{22}$ Delpino, L.: Diritto Penale. Parte Generale, Edizioni Giuridiche Simone, Napoli, p. 439.

${ }^{23}$ Vid. AnTOlisei, F.: Istituzioni di Diritto Penale, Ed. Giuffrè, Milano, 2000, p. 24I; DelPINO, L.: Diritto Penale. Parte Generale, Edizioni Giuridiche Simone, Napoli, p. 437.

${ }^{24}$ Bajo esta circunstancia se analiza y valora el estimulo que ha inducido al individuo a obrar, es decir, la causa psíquica de su acción, de suerte que la jurisprudencia italiana viene considerando la concurrencia de móviles o motivos abyectos cuando los mismos expresan una particular depravación y bajeza de ánimo y suscitan repugnancia en cualquier persona de moralidad media. Motivo fútil, o casos de pura y brutal maldad, concurren cuando el estimulo que ha provocado la acción del sujeto pone de manifiesto la desproporción de ésta respecto de aquel, lo que viene a implicar que el delito en realidad se debe a los propios instintos criminales del sujeto.

${ }^{25}$ La operatividad de esta agravante depende de que el delito haya sido cometido con alguna de las finalidades indicadas sin que sea preciso que el sujeto haya logrado su propósito.

${ }^{26}$ Nos encontramos ante la agravación en los casos de culpa consciente o con representación.

${ }^{27}$ La agravación por empleo de sevicias va referido a aquellos supuestos en los que el agente inflige a la víctima sufrimientos físicos o morales con medios tormentosos que no son necesarios

Redur 4 / 2006 
tiempo, de lugar o de persona obstaculizando la defensa pública o particular ${ }^{28}$; el haber cometido el culpable el delito durante el tiempo en que se ha sustraído voluntariamente a la ejecución de un mandado o de una orden de arresto o de captura o de encarcelación, en relación con un delito anterior; en los delitos contra el patrimonio, o que impliquen una ofensa o lesión del patrimonio, o en los delitos determinados por motivos de lucro, haber causado a la persona ofendida por el delito un daño patrimonial de importante gravedad $^{29}$; el haber agravado o intentado agravar las consecuencias del delito cometido ${ }^{30}$; el haber cometido el hecho con abuso de poder, o con violación de las obligaciones inherentes a una función pública o a un público servicio, o en calidad de ministro de un culto; el haber cometido el hecho contra un funcionario público o contra una persona encargada de un servicio público, o investida de la calidad de ministro del culto católico o de un culto admitido en el Estado, o contra un agente diplomático o consular de un estado extranjero, en el acto o a causa del incumplimiento de las funciones o del servicio ${ }^{3 \mathrm{I}}$; haber cometido el hecho con abuso de autoridad ${ }^{32}$ o de relaciones domesticas ${ }^{33}$, o con abuso de relaciones de oficio $^{34}$, de prestación de obra ${ }^{35}$, de cohabitación ${ }^{36}$ o de hospitalidad ${ }^{37}$.

para cometer el delito, mientras que la agravación por la crueldad contra las personas encuentra su fundamento en el especial desvalor de aquellos comportamientos que ponen de manifiesto una absoluta falta de sentimientos humanitarios dirigidos no ya sólo contra el sujeto pasivo del delito sino incluso contra un tercero.

28 Estamos refiriéndonos a aquellos supuestos en los que el sujeto activo se aprovecha intencionalmente, es decir, con conocimiento y voluntad, de una condición o circunstancia favorable de tiempo (como la oscuridad), de lugar (como el lugar aislado), o de persona (por ser la víctima deficiente, menor, hallarse embriagada, etc.), que implica una disminución de la defensa pública o particular.

${ }^{29} \mathrm{Al}$ objeto de valorar si nos encontramos ante un daño patrimonial de importante gravedad ha de atenderse por supuesto a la entidad objetiva del daño causado, aunque también podrá atenderse a la capacidad económica del afectado, pero sólo como criterio subsidiario de apreciación, para aquellos casos en los que el juez no considere suficiente por sí misma, para la apreciación de la circunstancia, el valor intrínseco de la cosa.

$3^{\circ}$ Esta circunstancia opera cuando tras la comisión del delito, el sujeto, con una ulterior acción, agrava o intenta agravar los efectos del mismo.

${ }^{3 \mathrm{I}}$ La tutela que representa esta circunstancia agravante más que proyectarse sobre el individuo lo hace sobre la función $u$ oficio.

${ }^{32}$ Hipótesis que habrán de ubicarse fuera de la agravante de abuso de poder antes vista. En este sentido, como señala PADOVANI, la autoridad debe de entenderse en sentido privado, ya que lo contrario supondría una confusión con la agravante de abuso de poder. Vid. PADovani, T.: Diritto Penale, Ed. Giuffrè, Milano, I990, p. 328.

33 Esta circunstancia contempla las relaciones existentes en la familia, entre sus miembros. Nuvolone, P.: Il Sistema del diritto penale, $2^{\text {a }}$ ed., Ed. CEDAM, Padova, I982, p. 432 ha precisado al respecto que la relación doméstica se da cuando se pertenece a un único núcleo familiar, aun cuando no existan entre los miembros relaciones de parentesco y falte cohabitación; del mismo modo opina PADOVAnI, T.: Diritto penale, Ed. Giuffrè, Milano, I990, p.328, para quien las relaciones domésticas consisten en la pertenencia a un mismo núcleo familiar, aunque no se encuentren caracterizadas por vínculos de pertenencia o afinidad; BETTIOL ha dicho al respecto que por abuso de relaciones domésticas hay que entender abuso relativo a las relaciones entre miembros de una misma familia, entendida en sentido lato como comprensiva no sólo de los individuos relacionados entre ellos por un vínculo de sangre, sino de todos aquellos que forman parte del circulo familiar, como domésticos o tutores, Vid. BetTIOL, G.: Diritto penale, Parte Generale, II $^{a}$ ed., Ed. CEDAM, Padova, I982, p. 535.

${ }^{34}$ Se refiere esta circunstancia a aquellas relaciones que nacen en el lugar en que se ejerce una actividad, o que surgen en el marco del ejercicio de la actividad misma. En este sentido, para 
Padovani, T.: Diritto penale, Ed. Giuffrè, Milano, I990, p.328, las relaciones de oficio se refieren a la participación, aunque ocasional, a una misma comunidad de trabajo.

${ }^{35}$ Se refiere este supuesto a aquellas relaciones que surgen de la prestación de un servicio de cualquier tipo. En este sentido la Cass.pen. 23.II.93, ap. II, GP, I994, II, 545 ha señalado que para la configurabilidad de esta agravante no hace falta que concurra una prestación de obra en sentido técnico, sino que ha de estarse al concepto más amplio de prestación de obra, englobando cualquier relación de carácter fiduciario, como la que existe entre el contratante y sus dependientes, de la que haya abusado el sujeto agente a la hora de perpetrar el delito; es decir, la expresión «relaciones de prestación de obra» en sentido amplio incluye en su significado no sólo la hipótesis de la relación o contrato de trabajo, sino todas aquellas relaciones jurídicas que, desde una más amplia y extensa acepción, conllevan la obligación de un facere. Como señaló la Cass.pen. II.I2.95, ap. VI, GP, I996, II, 7I5, en el delito de apropiación indebida, para la configurabilidad de la circunstancia agravante del art. GI, n. II, c.p., la expresión «abuso de relación de prestación de obra» abarca , además de la hipótesis de un contrato de trabajo, todas las relaciones jurídicas que comportan la obligación de un facere y que instauren entre las partes unas relaciones de confianza que agilice la comisión del hecho. De todos modos, al origen de la posesión de la cosa debe hallarse una relación jurídica valorable, que no se resuelva en una relación meramente ocasional y extemporánea, relativa a razones de simple amistad. Sin embargo la exigencia de una relación jurídica valorable se ha relativizado tanto por la doctrina como por la jurisprudencia. En este mismo sentido, como señaló NUVOLONE la relación de prestación de obra subsiste siempre que el agente esté vinculado, aún de forma ocasional, al sujeto pasivo por una relación jurídica, que lo empeña a llevar a cabo cualquier actividad en el interés de este último, Vid. Nuvolone, P.: Il Sistema del diritto penale, $2^{\mathrm{a}}$ ed., Ed. CEDAM, Padova, I982, p. 432. Para MANZINI, para que se de prestación de obra es suficiente una relación de mero hecho, permanente y ocasional, Vid. MANZINI, V.: Trattato di diritto penale italiano, $5^{a}$ ed., Ed. UTET, Torino, I98I, p. 227; por su parte la Cass.pen. 23.9.99, ap. V, CP, 2000, I ha establecido que con vistas a la apreciación en el delito de apropiación indebida, de la agravante de la relación de prestación de obra, es suficiente la existencia de una relación, también de tipo meramente factual, que haya representado al menos ocasión, si no también razón jurídica, de la posesión por parte del imputado, y que haya por lo tanto permitido a este último cometer con mayor facilidad el delito, sirviéndose de la particular confianza en él puesta.

${ }^{36}$ Como señaló MANZINI, las relaciones de cohabitación se dan siempre que subiste un estado de hecho, por el que una o más personas se encuentren reunidas por la vida domestica o por cualquier acto de dicha vida, en un mismo lugar durante un tiempo Vid. MAnZINI, V.: Trattato di diritto penale italiano, $5^{\text {a }}$ ed., Ed. UTET, Torino, I98I, p. 23I. La Cass.pen. 26.9.95, ap. II, I997, I335 ha establecido al respecto que con vistas a la configurabilidad de la agravante según el art. 6i n. II c.p., la relación de cohabitación viene dada por la circunstancia objetiva de la convivencia más o menos extendida en el tiempo y, de todas formas, durante un periodo estimable, no sólo en una misma vivienda o piso, sino también, según un concepto más amplio del término «cohabitación», en el mismo inmueble. A estos efectos es indiferente que la causa de la cohabitación sea voluntaria, fortuita o coactiva; se dice, en este sentido, que las necesidades de la vida crean a menudo situaciones en las que la cohabitación está determinada por las circunstancias de necesidad del caso, antes que por la voluntad de los cohabitantes. En dichas hipótesis hay una mayor razón para poder aplicar la agravante, justo porque no está presente la libre elección de las personas con las que se tiene que vivir. La circunstancia no puede excluirse de la cohabitación coactiva, que es también casual respecto a la voluntad de los cohabitatores. Vid. MANZINI, V.: Trattato di diritto penale italiano, 5 a ed., Ed. UTET, Torino, I98I, p. 233; en el mismo sentido, ha señalado PADOVANI, que las relaciones de cohabitación conciernen la puesta en común del espacio habitativo, aunque sea involuntaria, Vid. PADOVANI, T.: Diritto penale, Ed. Giuffrè, Milano, ı990, p.328.

37 Supuestos de relaciones originadas por la convivencia en un mismo lugar o por la permanencia, también de breve duración, en otros por cualquier causa. Para NuVOLONE, P.: II Sistema del diritto penale, $2^{\text {a }}$ ed., Ed. CEDAM, Padova, I982, p. 432 se da la hospitalidad cuando hay cohabitación, aunque momentánea y ocasional, por lo cual el agente es recibido y puede detenerse lícitamente, aunque sea durante un breve tiempo, en el domicilio del sujeto pasivo; PADOVANI señala que las relaciones de hospitalidad implican la acogida de una persona en un espacio en el que el que hospeda ejerce un ius excludendi, Vid. PAdovani, T.: Diritto penale, Ed. Giuffrè, Milano, I990, p. 328; señalando MANZINI que la relación de hospitalidad se produce entre el hospedado y el que hospeda. No hay relaciones de hospitalidad entre los hospedados por una misma persona. El delito

Redur 4 / 2006 


\section{Las circunstancias atenuantes comunes o generales.}

El art. 62 del Codice penale contempla como circunstancias atenuantes comunes o generales las siguientes: el haber actuado por motivos de particular valor moral o socia ${ }^{38}$; el haber reaccionado en estado de ira, determinado por un hecho injusto ajeno ${ }^{39}$; el haber actuado por sugestión o impulsos de una multitud en tumulto ${ }^{40}$, cuando no se trate de reuniones o agrupaciones prohibidas por la ley o por la autoridad, y el culpable no sea delincuente o contraventor habitual, o profesional, o delincuente por tendencia; en los delitos contra el patrimonio, o que impliquen una ofensa o lesión del patrimonio, haber causado a la persona ofendida por el delito un daño patrimonial de especial levedad, o en los delitos determinados por motivos de lucro, haber actuado para conseguir, o haber conseguido de hecho un lucro de especial levedad, cuando también el evento dañoso o peligroso sea de especial levedad ${ }^{4 \mathrm{I}}$; el haber concurrido a la causación del evento junto a la acción u omisión del culpable, un hecho doloso de la persona ofendida; el haber, antes del juicio, reparado totalmente el daño, mediante el resarcimiento del mismo y, cuando sea posible, mediante la correspondiente restitución; o el haberse, antes del juicio y fuera del caso previsto en el último párrafo del art. 56 , empleado espontánea y eficazmente para eludir o atenuar las consecuencias dañinas o peligrosas del delito ${ }^{42}$.

perpetrado por un hospedado que daña otro hospedado no está agravado por la circunstancia de la que hablamos, si la hospitalidad no determina cohabitación, Vid. MANZINI, V.: Trattato di diritto penale italiano, $5^{\mathrm{a}}$ ed., Ed. UTET, Torino, I98I, p. 235.

${ }^{38}$ Esta circunstancia viene a ser la antítesis de actuar por motivos abyectos o fútiles contemplada como circunstancia agravante común en el número i del art. 6i del Codice. Como motivos de particular valor moral podrían señalarse aquellos que se concretan en acciones moralmente nobles a la luz de la conciencia ética del pueblo en un momento histórico determinado, mientras que por motivos de particular valor social hay que entender aquellos que van referidos a las «directivas $y$ finalidades de la comunidad organizada». Vid. ANTOLISEI, F.: Istituzioni di Diritto Penale, Ed. Giuffrè, Milano, 2000, op. cit., p. 246.

39 Son las hipótesis de la llamada «provocación»; no se requiere que la reacción tenga lugar inmediatamente después del hecho determinante, de suerte que un cierto intervalo temporal entre la ofensa y la reacción no excluye la atenuante siempre que el citado estado de ira permanezca o se vuelva a encender en el momento del delito; del mismo modo basta con que el hecho determinante de la ira sea injusto desde una perspectiva moral sin necesidad de que sea injusto jurídicopenalmente, y sin que sea preciso, por otra parte, para la apreciación de la atenuante, que la reacción sea proporcionada al hecho injusto determinante de la ira.

$4^{\circ}$ Por tumulto debe entenderse una situación de confusión turbulenta de personas sin que sea preciso que alcance el grado de sublevación, insurrección o revolución.

${ }^{{ }^{\mathrm{I}}}$ Se trata de una circunstancia que viene a ser parcialmente la antítesis de la circunstancia agravante número 7 del artículo 6I.

$4^{2}$ El fundamento de esta circunstancia se encuentra en el arrepentimiento del culpable, que se pone de manifiesto tras la consumación del delito y que se concreta en una acción dirigida a reparar las consecuencias del mismo. Dicha reparación debe tener lugar antes del juicio y por lo tanto no es operativa si ocurre tras la apertura del debate. La circunstancia se divide en dos hipótesis, según la reparación del daño ocurra por medio del resarcimiento (o eventualmente de las restituciones), o mediante la elusión o la atenuación de las consecuencias del hecho delictivo. El resarcimiento debe ser integral, es decir cubrir por entero el daño y debe tener lugar de forma voluntaria. Respecto a la actuación del sujeto dirigida a la elusión o la atenuación de las consecuencias del hecho delictivo el precepto se refiere a aquellos casos en los que no cabe la restitución ni el resarcimiento, aludiéndose a conductas del agente dirigidas a evitar o aminorar las consecuencias de su precedente conducta delictiva. También en éste último supuesto la conducta del agente, para que haya lugar a la apreciación de la circunstancia atenuante analizada, debe ser voluntaria, libre y espontánea, es decir

Redur 4 / 2006 
V. Las circunstancias atenuantes genéricas.

determinada por motivos internos y no por presiones exteriores. Sobre esta circunstancia, y si bien no faltan resoluciones judiciales que creen ver en ella una circunstancia puramente utilitarista, objetiva y cuya ratio descansaría en la mera reparación del daño (Vid. Cass.pen. I8.I2.8I, ap. III, I982, II, 290), lo cierto es que la mayoría de la doctrina y la jurisprudencia la consideran una circunstancia de carácter personal cuya ratio o fundamento más que en la reparación del daño descansa en la persona o personalidad del autor del delito (Vid. ZAZA, C.: Le circostanze del reato, Vol. I, Elementi generali e circostanze comuni, Ed. Cedam, Padova, 2002, p. 62 a 65). En este sentido, la Cass. pen. 3.I2.87, ap. I, GP, I989, II, I48, sentó que en relación con la circunstancia del art. $62 \mathrm{n}^{\circ} 6$, el legislador ha tomado en consideración no tanto la función instrumental de la satisfacción del interés de la persona ofendida por el delito, como el perfil psicológico y voluntarista del culpable (el carácter voluntario de la actividad del agente es destacado también por la Cass.pen. I8.4.89, ap. IV, GP, I990, II, IO2 al señalarse que para la apreciación de esta atenuante la reparación debe ser voluntaria, ya que el resarcimiento debe considerarse no tanto desde la perspectiva de la satisfacción de los intereses civiles, como en función de la conducta del culpable posterior a la comisión del delito, como síntoma de su arrepentimiento y de atenuada capacidad para delinquir), es decir la conducta tenida después del delito como síntoma de la atenuada capacidad para delinquir del reo, de suerte que «...es suficiente la demostración de la real voluntad del culpable, que se debe poder comprobar de forma incontrovertible por medio de un comportamiento que denote la misma (...) Por lo tanto la oferta de resarcimiento como oferta real, aunque no seguida de deposito efectuado de modo formal, determinando una concreta devolución de la suma a favor del perjudicado, y aunque rechazada por la parte perjudicada, constituye un elemento idóneo para la aplicación de la atenuante»; por su parte, la Cass.pen. I6.3.90. ap. II, GP, I990, II, 6I4, ha sentado que la circunstancia atenuante prevista por el art. 62 n. 6 , primera hipótesis, posee una naturaleza subjetiva, y la correspondiente disminución de la pena encuentra su justificación no tanto en la restauración del patrimonio de la victima, como en la consideración que el resarcimiento efectuado del daño o restitución anteriormente al juicio se presenta como una manifestación concreta del sobrevenido arrepentimiento del reo, y por lo tanto de su menor peligrosidad; en el mismo sentido la Cass. Pen. 7.I.93, ap. V, CP, I994, I5IO señala que: «El art. $62 n^{\circ} 6$ configura una atenuante condicionada al hecho de que el culpable antes del juicio haya reparado por entero el daño a través de su resarcimiento y, cuando sea posible, a través de la restitución. Se trata de una atenuante de tipo exclusivamente subjetiva, que se ve justificada no tanto en los intereses económicos de la persona ofendida, como en la importancia que la indemnización del daño anteriormente al juicio adquiere como prueba tangible del arrepentimiento del reo y por lo tanto de su menor peligrosidad social»; si lo anterior es así, es lógico que la jurisprudencia haya sentado, asimismo, que la atenuante de la reparación del daño es apreciable tan sólo en relación con la libre determinación volitiva del imputado sin que pueda apreciarse cuando responda a la actividad de terceras personas (Cass. Pen. II.I.82, ap. II, Gp, I982, II, 708); o que «la atenuante del art. 62 n.6 es apreciable sólo si la acción dirigida a atenuar las consecuencias dañinas o peligrosas del delito es espontánea, es decir determinada por motivos internos al agente, independientemente de su tipo, y no influenciada de ninguna manera por factores externos que operen compresión en el empuje psicológico» (Cass.pen. 23.II.82, ap. II, GP, I984, II, 28), y que del mismo modo resulte difícilmente apreciable esta circunstancia por la jurisprudencia cuando el resarcimiento tiene lugar mediante la reparación efectuada por una compañía aseguradora (Vid. Cass.pen. 4.Io.82, ap. IV, GP, I983, II, 486; Cass.pen. I6.2.82, ap. IV, GP, I983, I, 222; Cass.pen. 28.2.84, ap. IV, GP, I985, II, 2I4; Cass. Pen. 20.10.89, ap. IV, GP, I990, II, 468; Cass.pen. II.I0.90, ap. IV, GP, I99I, II, 227; Cass.pen. 22.4.9I, ap., IV, GP, I992, II, 42; Cass.pen. I0.3.93, ap. IV, GP, I993, II, 62I, entre otras). En la Cass.pen, 28.6.9I, ap. VI, GP, I99I, II, 733 se sentó que la atenuante del art. $62 \mathrm{n}^{\circ} 6$ es de tipo subjetivo y encuentra su justificación en la menor capacidad para delinquir del culpable, que, por arrepentimiento, después de la consumación del delito, pero antes del juicio, se esmera para evitar o atenuar las consecuencias dañinas o peligrosas del delito, no pudiéndose apreciar en relación con un comportamiento procesal de mera colaboración con los órganos investigadores, cuando dicha colaboración no resulte determinante de una menor capacidad para delinquir o de un arrepentimiento en los términos antes indicados, sino que se encuentre inspirada en previsiones meramente utilitarias de reducción de la pena, o cuando la confesión no tenga incidencia alguna, ni potencial, en la elusión o atenuación de las consecuencias dañinas del delito.

Redur 4 / 2006 
En el art. 62 bis del Código penal italiano -proveniente de la introducción que tuvo lugar en el Codice por el D.L.L. de I4 de septiembre de I944, $\mathrm{n}^{\circ} 288$ - se ha contemplado expresamente la posibilidad de atenuar la pena por la concurrencia de circunstancias genéricas no contempladas expresamente en la Ley al disponerse que: «EI juez, independientemente de las circunstancias previstas en el art. 62, puede tomar en consideración otras circunstancias diferentes, allí donde lo considere oportuno para justificar una disminución de la pena. En tal caso, las mismas serán consideradas, al objeto de aplicar este apartado, como una sola circunstancia, pudiendo concurrir con una o varias de las circunstancias indicadas en el precedente art. 62» ${ }^{43}$.

El fundamento o razón de ser de las circunstancias atenuantes genéricas suele residenciarse en que no puede negarse la existencia, al margen de las previsiones expresamente contempladas normativamente, de situaciones y circunstancias que efectivamente inciden en la «cantidad» del delito y en la capacidad de delinquir del sujeto, de manera que contemplar esta realidad extranormativa permite llegar a una más válida y acertada valoración de los elementos que determinan los parámetros para la concreción de la pena que debe imponerse en el caso $^{44}$. Se trata, en suma, de que las circunstancias atenuantes genéricas contribuyen decisivamente a la individualización y proporcionalidad ${ }^{45}$ de la pena, a la adecuación de la pena al caso concreto por medio de una más completa y unitaria valoración del hecho delictivo en sus aspectos subjetivos y objetivos ${ }^{46}$, adecuación

43 La Legge de 5 de diciembre de 2005, n. 25I, de «Modifiche al codice penale e alla legge 26 luglio 1975, n. 354, in materia di attenuanti generiche, di recidiva, di giudizio di comparazione delle circostanze di reato per i recidivi, di usura e di prescrizione» introduce un segundo párrafo al precepto, estableciendo ahora además: «Ai fini dell'applicazione del primo comma non si tiene conto dei criteri di cui all'articolo I33, primo comma, numero 3), e secondo comma, nei casi previsti dall'articolo 99, quarto comma, in relazione ai delitti previsti dall'articolo 407, comma 2, lettera a), del codice di procedura penale, nel caso in cui siano puniti con la pena della reclusione non inferiore nel minimo a cinque annis. En realidad, la posibilidad de atenuar la pena por la concurrencia de circunstancias genéricas no contempladas de modo especifico en la ley, ya había sido contemplada por el art. 59 del Código Zanardelli. Respecto a estas atenuantes genéricas, la doctrina ha venido señalando que las mismas se insertarían dentro de la más amplia categoría de las circunstancias indefinidas. Vid. ZAZA, C.: Le circostanze del reato, Vol. I, Elementi generali e circostanze comuni, Ed. Cedam, Padova, 2002, p. 36.

${ }^{44}$ Vid. Cass. Pen. 20.I.83, ap.I, GP, I984, II, 27; Cass. Pen. 23.8.90, ap. II, GP, I99I, II, 226. En la Cass. pen. I0.2.84, ap. I, GP, I985, II, 90 se señaló que las circunstancias atenuantes genéricas tienen sentido desde el momento en que el legislador no ha podido preverlo todo expresamente en orden a la individualización de la pena, y ello dada la imposibilidad de concretar en una formula de estilo la inmensa variedad de posibles eventos fácticos y humanos; con las circunstancias atenuantes genéricas corresponde al juez captar, en lo concreto de cada caso, en los motivos que lo han determinado, en las circunstancias que lo han acompañado, aquellos elementos que pueden sugerir la necesidad de atenuar la pena prevista por el legislador; en el mismo sentido se han pronunciado múltiples resoluciones, así la Cass. pen. 3.3.90, ap. VI, GP, I990, II, 6I3 establece que las circunstancias genéricas del art. 62 bis c.p. se refieren a lo que en concreto el legislador no ha podido prever, con vistas a la individualización y personalización de la pena, y ello debido a la imposibilidad de englobar en una fórmula de alcance general y abstracto la inmensa variedad de los eventos posibles, por ello «...con respecto a los criterios indicados en el art. I33 c.p., ha atribuido al juez, en lo concreto del hecho-delito, la facultad de captar en los motivos que lo han determinado, en las circunstancias que lo han acompañado, en el daño efectivo que ha causado, aquellos elementos que pueden sugerir la necesidad de atenuar la pena prevista por el legislador concretamente para el delito de que se trate».

45 Vid. Cass. Pen. I0.4.95, ap. VI, CP, I996, 3640. Los jueces desarrollan así una labor de corrección para hacer la pena concreta respetuosa con los principios de razonabilidad y proporcionalidad.

${ }^{46}$ Vid. Cass. Pen. 20.II.8I, ap. I, GP, I982, II, 404; Cass. Pen. 27.6.84, ap. I, GP, I985, II, 269; Cass. Pen. 29.9.86, ap. I, GP, I987, II, 624; como señaló MALInVERni, A.: «Circostanze del reato», 
que no podría alcanzarse, de manera plena y efectiva, a través del riguroso principio de determinación normativa concreta y taxativa de las circunstancias, en la medida en que existen multitud de situaciones que pueden tener importancia al objeto de valorar la gravedad del delito y la capacidad delictiva del sujeto pero que sin embargo pueden no resultar en principio previsibles desde una perspectiva normativa ${ }^{47}$. Por ello no puede negarse ya, desde este momento, que la misma existencia de las circunstancias atenuantes genéricas genera una clara tensión entre los principios de legalidad y de justicia material ${ }^{48}$.

en Enciclopedia del Diritto, VII, Ed. Giuffrè, Milano, I960, p. 94, las atenuantes genéricas cumplen una función de corrección de la pena respecto al hecho y a la personalidad del agente.

47 Vid. Mantovani, F.: Diritto penale: Parte generale, Ed. CEDAM, Padova, I979, p. 36r; Vid. Cass. Pen. 2I.I.99, ap. V, GP, 2000, II, 243. Como señala MASSA, M.: Le Attenuanti generiche, Ed. Eugenio Jovene, Napoli, I959, p. 85, existen ciertas situaciones en las que ya por las características del desarrollo de la acción, o incluso por ciertas cualidades de la propia acción, se podría decir que algunos matices de la misma tienen un significado idóneo para influenciar el juicio sobre el agente y conducir en suma a determinar una disminución de la pena; la ley no especifica cuales sean dichas situaciones o cualidades, pero obliga al juez a buscarlas por si mismo, directamente en la realidad, en el análisis del hecho criminal y sus circunstancias. En el sistema de las circunstancias italiano no puede afirmarse que rija un sistema de taxatividad puro, y ello por cuanto al margen del vasto y amplio campo de las circunstancias definidas, expresamente previstas en la Ley, existen también circunstancias indefinidas o innominadas, que si bien se trata de verdaderos supuestos excepcionales (Vid. Bricola, F.: Scritti di diritto penale, a cura di Canestrari e Melchionda, vol. I, Ed. Giuffrè, Milano, I997, p. 342 y ZAZA, C.: Le circostanze del reato, Vol. I, Elementi generali e circostanze comuni, Ed. Cedam, Padova, 2002, p. 43), su individualización corresponde, en mayor o menor medida al Juez. Respecto a las circunstancias atenuantes genéricas, éstas son comunes a todos los delitos, de suerte que la ley se limita a decir que deben ser diferentes de las previstas en el art. 62 y remite su individuación a la discrecionalidad del juez, que deberá motivar su concesión o su rechazo, Vid. MANTOVAnI, F.: Diritto penale: Parte generale, Ed. CEDAM, Padova, I979, p. 343, 362.

${ }^{48}$ En Italia hace tiempo se suscitó un debate dogmático acerca de si las circunstancias atenuantes genéricas venían a ser una suerte de circunstancias impropias o institución sui generis, o bien, y por el contrario, se trataba de auténticas circunstancias en sentido estricto o propio. Así BRICOLA se refería a que tanto la jurisprudencia como un sector de la doctrina eran proclives a considerar el art. 62 bis como un apéndice del art. I33 del Codice penale, dirigido funcionalmente a lograr una reducción de la pena por debajo del mínimo edictal. Vid. BRICOLA, F.: Scritti di diritto penale, a cura di Canestrari e Melchionda, vol. I, Ed. Giuffrè, Milano, I997, p. 309, y que por tanto no integraría en su seno a auténticas circunstancias, sino que estaríamos más bien ante una institución especial, circunstancias impropias, relativas a la determinación de la pena o no genuinas, o como señaló MASSA, se encuadrarían en realidad fuera del marco de las «verdaderas circunstancias en sentido técnico», quedando fuera del concepto técnico de circunstancia (Vid. MASSA, M.: Le Attenuanti generiche, Ed.Eugenio Jovene, Napoli, I959, p. I87), defendiéndose por otros autores que, en la medida en que las circunstancias atenuantes genéricas no intervenían en la tipicidad del hecho debía descartarse su condición de circunstancia (Vid. ZAZA, C.: Le circostanze del reato, Vol. I, Elementi generali e circostanze comuni, Ed. Cedam, Padova, 2002, p. 38 ss. criticando tal forma de razonar). Sin embargo, es lo cierto que la doctrina más autorizada en Italia, hoy no duda de que las circunstancias atenuantes genéricas son verdaderas circunstancias en sentido estricto. En este sentido, para Bricola F.: Scritti di diritto penale, a cura di Canestrari e Melchionda, vol. I, Ed. Giuffrè, Milano, I997, p. 309: «Según una más reciente y acertada caracterización, la institución, estructuralmente diferenciada por la ausencia de un paradigma normativo, desvelaría una función análoga a la de las circunstancias propias: permitir que el juez absorba un valor positivo del hecho, diferente de los fijados ex art. 62 c.p.»; para MASSA se trata, tanto atendiendo a su esencia como a su eficacia normativa de auténticas circunstancias, señalando que se «... trata de elementos accidentales que, sea el que sea el aspecto del ilícito en el que hacen hincapié, conllevan efectos del todo idénticos a los que siguen a las demás circunstancias, es decir, una modificación de la pena», Vid. MASSA, M.: Le Attenuanti generiche, Ed. Eugenio Jovene, Napoli, I959, p. I89. En el mismo sentido, PADOVANI, T.: Diritto penale, Ed. Giuffrè, Milano, I990, p.309 considera también que las circunstancias atenuantes genéricas son auténticas circunstancias y no deben ser confundidas con los «...coeficientes de graduación de la pena contenidos en el art. I33 del Código penal», además, como señala PADOVANi las circunstancias permiten superar los límites máximos y mínimos de la pena

Redur 4 / 2006 
El principio de legalidad cumple una obvia y evidente función de garantía pero adolece de problemas prácticos indudables, como la rigidez y ausencia de previsión de las connotaciones específicas del caso concreto, de este modo, las circunstancias atenuantes genéricas constituyen ese instrumento flexible e idóneo para la conjunción de legalidad y justicia material, para alcanzar en suma una pena adecuada al hecho concreto a través de la compenetración de garantía y flexibilidad ${ }^{49}$.

previstos por la ley para el delito, mientras que los coeficientes del art. 133 del Codice explican su función precisamente dentro de estos límites; en el mismo sentido se ha pronunciado ROMANO, M.: Commentario sistematico del codice penale, V. I, $2^{a}$ ed. ren. y amp., Ed. Giuffré, Milano, I995, p. 645 reconociendo el carácter de auténticas circunstancias a las atenuantes genéricas en base a criterios puramente semánticos y terminológicos al señalar que «El art. 62 bis es univoco al indicar que las circunstancias se consideran en cada caso como una sola circunstancia: por un lado esto significa que ante la presencia de una pluralidad de factores, todos susceptibles en la situación concreta de considerarse como atenuantes, deberán confluir en una única circunstancia; por otro lado la expresión confirma que las atenuantes genéricas son iguales a las demás: implican una disminución de pena según el art. 65 y concurren con las demás circunstancias comunes o con eventuales circunstancias especiales según los arts. 63 y 67 , justo porque son consideradas en sentido técnico como si se tratase de circunstancias nominadas». Como se ha visto la modificación del Código penal operada por la Ley $25 \mathrm{I} / 2005$ ha afectado directamentea este precepto, de manera que en la actualidad se han introducido excepciones a las previsones del primer párrafo del precepto. La jurisprudencia por su parte también ha acabado por reconocer que las mismas presentan una naturaleza de auténticas circunstancias; así en la Cass.pe. I9.I.83, ap. III, GP, I984, II, 30, señaló que: «la atenuante prevista por el art. 62 bis, aun teniendo naturaleza facultativa y basándose en elementos diferentes de aquellos que permiten la concesión de otras atenuantes, se incluye entre las circunstancias atenuantes comunes y sigue, bajo cada aspecto, su régimen jurídico».

49 ZAZA, C.: Le circostanze del reato, Vol. I, Elementi generali e circostanze comuni, Ed. Cedam, Padova, 2002, p. 52. Para MAGgione, G.: Diritto penale. Parte generale, ${ }^{a}$ ed., Ed. Zanichelli, Bologna, I958, p. 532 la institución de las circunstancias innominadas remitidas al albedrío del juez con el solo objetivo de hacer menos dura la pena, aun bajando por debajo del mínimo edictal, es un instrumento, quizás el único eficiente, de individualización y de personalización de la pena, es, en suma «el medio más humano de ajustar el derecho a la justicia, representando el triunfo de la equidad sobre la legalidad, al que debe aspirar cada ordenamiento penal fundado en bases éticas». Respecto a cuáles puedan ser las situaciones generadoras de la apreciación de una circunstancia atenuante genérica, lo cierto es que no pueden predicarse reglas exactas al respecto. PAGLIARO, A.: Principi di diritto penale. Parte generale, $4^{a}$ ed., Ed.: Giuffrè, Milano, I993, p. 469 señaló que no es posible indicar de forma precisa cuáles puedan ser las situaciones capaces de integrar una circunstancia atenuante genérica, si bien, precisó, se pueden deducir criterios, a modo de máxima, del mismo art. I33, pues «dicho precepto determina los principios generales, de los que se hace depender la conmensuración de la pena en el ámbito de los límites edictales, y por lo tanto expresa el punto de vista del ordenamiento acerca de lo que puede justificar una disminución de pena», pudiendo considerarse a estos efectos circunstancias tanto relativas al hecho como al autor. MANZINI, V.: Trattato di diritto penale italiano, $5^{2}$ ed., Ed. UTET, Torino, I98I, p. 308 señaló que han de ser tomados en consideración a estos efectos como causas que, aun no disminuyendo especificadamente la imputabilidad, sin embargo sí son un índice de una menor peligrosidad criminal del sujeto, factores como la subsistencia o no de concausas en la producción del evento, la ignorancia o error de derecho, el obrar motivado por un impulso de honor, o por hábito, por exceso de ahínco; la presencia de dificultades económicas, la ignorancia o escasa inteligencia del sujeto, la turbación de ánimo, el temor reverencial, la edad senil, delito cometido por mujeres con prole o embarazadas o con regla, vida anterior laboriosa y no censurada, tenuidad o nulidad del daño, espontánea autodenuncia o confesión sincera y completa ante la Autoridad, proximidad a una causa extintiva del delito, sensibilidad a la pena mayor de la media, condición de extranjero o ajeno por lo que se refiere a las contravenciones de policía y fiscales, entre otros. En cualquier caso, y al respecto, la jurisprudencia de los años ochenta vino considerando que la apreciación de estas circunstancias venía a consistir en una especie de «indulgencia» o «particular benevolencia» concedida por el Juez, en el caso concreto, como gracioso beneficio discrecional para atemperar la rigurosidad de las penas. 
VI. La imputación de las circunstancias modificativas de la responsabilidad criminal.

En relación con la imputación de las circunstancias modificativas de la responsabilidad criminal ha tenido especial trascendencia en Italia la reforma del artículo 59 del Codice Penale llevada a cabo por la Ley número I9, de 7 de febrero de $1990^{50}$. Con anterioridad a dicha reforma, el citado precepto establecía que salvo que la ley lo dispusiera de otro modo, las circunstancias que agravaban, atenuaban o excluían la pena, deberían ser apreciadas, respectivamente, en contra o a favor del agente, aunque no las conociera o por error las hubiera creído inexistentes; del mismo modo, se disponía, si el agente creyera por error que existían circunstancias agravantes, o atenuantes, éstas no serían apreciadas ni en contra ni a favor suyo. En la actualidad, el citado artículo 59, en relación con las circunstancias no conocidas o erróneamente supuestas establece que las circunstancias que atenúan (arts. 62, 62-bis y II4) o excluyen la pena, se valorarán a favor del agente aunque las desconozca, o por error las considere inexistentes, mientras que las circunstancias que agravan la pena se valorarán a cargo del agente sólo si él las conoce o las ignora por culpa o las considera inexistentes por error determinado por la culpa. Respecto a los casos en los que el agente considera por error que existen circunstancias agravantes o atenuantes, éstas no se valoran en contra ni a favor del mismo y si el agente considera por error que existen circunstancias de exclusión de la pena, éstas son siempre valoradas a su favor; no obstante, si se trata de un error determinado por culpa, la punibilidad no se excluye cuando el hecho está previsto por la ley como delito culposo.

Vid. en este sentido la Cass. pen. 2.10.83, ap. V, GP, I984, II, 469 establece que: «...la concesión de las circunstancias atenuantes genéricas debe fundarse en la comprobación de situaciones idóneas a justificar una particular benevolencia hacia el reo...»; la Cass. pen.I7.6.83, ap. I, GP, I984, II 4I6, señala que: «...si es verdad que el imputado es libre de negar, también por medio de falsedades, las acusaciones, y de substraerse por contumacia al arresto, es también verdad que el juez puede por dichos comportamientos considerarlo no merecedor de aquella particular indulgencia que es fundamento de las circunstancias atenuantes genéricas»; en la Cass. pen. I5.6.83, ap. I, GP, I984, II, 350, se estableció que «La recuperación de las circunstancias atenuantes genéricas ha sido establecida (...) con el objetivo de ofrecer al juez el medio para hacer menos graves las penas establecidas por el código penal, que fueron consideradas demasiado rigurosas». La doctrina ha criticado severamente la consideración que la Corte di casazione tiene de estas circunstancias atenuantes genéricas ya que en opinión de la doctrina mayoritaria no cabe confundir facultad discrecional de apreciación con el carácter de verdadera «indulgencia» que con ocasiones se predica acerca de estas circunstancias por algunas sentencias. Vid. MASSA, M.: Le Attenuanti generiche, Ed.Eugenio Jovene, Napoli, I959, p. 42 y MANZINI, V.: Trattato di diritto penale italiano, 5 ad., Ed. UTET, Torino, I981, p. 309. El art. 62 bis en modo alguno concede al Juez un poder indefinido de indulgencia, no se trata de una «amorfa benignitas» o de una «equidad subjetiva», ya que las circunstancias atenuantes genéricas son discrecionales, pero no facultativas. Vid. en este sentido a Romano, M.: Commentario sistematico del codice penale, V. I, $2^{\text {a }}$ ed. ren. y amp., Ed. Giuffré, Milano, I995, p. 646. Por su parte, la jurisprudencia más reciente se aparta también de la antigua concepción sobre las mismas: en este sentido, en la Cass. Pen. 28.6.90, ap. II, CP, I992, 3032 se afirma que las atenuantes genéricas «...no constituyen objeto de "concesión" para una mejor adecuación de la pena. La determinación de la pena se actúa exclusivamente con referencia a los parámetros indicados por la ley (gravedad del delito, capacidad de delinquir del culpable). Las atenuantes genéricas se reconocen ya que inciden en la valoración de dichos elementos, cuando existan fuera de las circunstancias atenuantes comunes o especificas y de las condiciones enumeradas en el art. I33 c.p.»; del mismo modo, en la Cass. Pen. I4.I.99, ap. VI, CP, 2000, 370 se sentó que: «...las atenuantes genéricas no deben de entenderse como objeto de benévola y discrecional "concesión" del juez, sino como el reconocimiento de situaciones no contempladas especificadamente...».

${ }^{50}$ Vid. DelPino, L.: Diritto Penale. Parte Generale, Edizioni Giuridiche Simone, Napoli, pp. 45045 I.

Redur 4 / 2006 
En relación con los supuestos de error sobre la persona del ofendido, el artículo 60 del Codice establece una solución expresa a estos supuestos señalando que en tales casos no se ponen a cargo del agente las circunstancias agravantes que conciernen a las condiciones o cualidades de las personas ofendidas, o las relaciones entre el ofendido y el culpable ${ }^{5 \mathrm{I}}$, mas sin embargo se valoran a su favor las circunstancias atenuantes, erróneamente supuestas, que conciernen a las condiciones, las cualidades o las relaciones anteriormente dichas ${ }^{52}$, sin que lo dispuesto en el art. 6o sea aplicable a los supuestos de circunstancias concernientes a la edad $u$ otras condiciones o cualidades, físicas o psíquicas, de la persona ofendida ${ }^{53}$.

\section{El juicio de comparación o equivalencia.}

Para los supuestos de concursos heterogéneos de circunstancias, es decir, para los casos en los que en un mismo supuesto concurran al unísono circunstancias atenuantes y agravantes, el art. 69 del Codice penale ${ }^{4}$ consagra la regla del juicio de comparación o equivalencia, dejando en manos del juzgador un amplio margen de discrecionalidad -no revisable en casación $n^{55}$ - en la determinación de la pena ${ }^{56}$. Ahora bien, ese juicio de

${ }^{5 \mathrm{I}} \mathrm{Si}$ el agente deseaba matar a un particular pero por error mata a un sacerdote no se le aplicará la agravación de haber cometido el delito contra un ministro del culto católico contemplada en el art. 6r.ıo del Codice.

$5^{2}$ En estos supuestos al agente se le trata jurídico-penalmente como si no hubiera ocurrido el error in personam, esto es, como si el delito hubiera ocurrido según el plan fijado por el agente: el delito putativo equivale al delito real, aunque esto no ocurre en todo caso ya que las circunstancias agravantes que se supongan erróneamente no pueden imputarse al agente.

${ }^{53}$ El error in personam no es un error esencial sino inesencial ya que, como señala ANTOLISEI, el ordenamiento jurídico tutela determinados bienes sea quien sea el titular. Vid. ANTOLISEI, F.: Istituzioni di Diritto Penale, Ed. Giuffrè, Milano, 2000, op. cit., p. 250-25I.

${ }^{54}$ La compensación de circunstancias está prevista en el Código penal italiano desde la reforma de II de abril de I974 (Ley de 7 de junio de i974) que modificó el art. 69 del Código penal, de suerte que antes de dicha reforma, las circunstancias generales y especiales no podían ser objeto de un juicio de ponderación o comparación, lo que si resulta posible a partir de la misma.

${ }^{55}$ Vid. Antolisei, F.: Istituzioni di Diritto Penale, op. cit., p. 253.

${ }^{56}$ La Cass.pen. I5.I2.83, ap. IV, GP, I984, II, 470 estableció que: «Con vistas a la comparación de las circunstancias en el sistema penal vigente, el criterio general, que debe observarse por parte del juez, es el que procede del esquema del art. I33 del Codice; de la coordinación de dicha norma con el art. 69 del mismo Código se deduce que el juez debe hacer el juicio de comparación, en el ejercicio de su poder discrecional, con el fin de obtener una valoración completa del hecho delictivo que, aun sin renegar el principio de la proporción entre la pena y el delito, tenga en cuenta, a la hora de determinar la pena que se debe infligir en concreto, la particular personalidad del reo, considerado cada aspecto sintomático de la misma y la sustancial entidad de la conducta criminab. Los supuestos de concurso entre varias circunstancias homogéneas, ya sean circunstancias atenuantes o ya sean circunstancias agravantes, darán lugar a tantos aumentos o disminuciones de pena cuantas sean las circunstancias concurrentes, todo ello conforme a los arts. 63 a 68 del Codice penale. Ahora bien, la acumulación material no operará en dos supuestos: en relación con las circunstancias específicas y en los supuestos de circunstancias complejas. En los supuestos de circunstancias complejas, éstas comprenden en sí mismas a otra u otras, dando lugar a la absorción de éstas por aquellas y a la aplicación tan sólo de la circunstancia de mayor entidad. En este sentido, el artículo 68 del Codice establece como límites al concurso de circunstancias que salvo lo dispuesto en el art. I5, cuando una circunstancia agravante incluya en sí a otra circunstancia agravante, o cuando una circunstancia atenuante incluya en sí a otra circunstancia atenuante, se valorará a cargo o a favor del culpable sólo la circunstancia agravante o la circunstancia atenuante, que aporte, respectivamente, el mayor aumento o la mayor disminución de pena, y si las circunstancias agravantes o atenuantes aportan el mismo aumento o la misma disminución de pena, se aplicará un solo aumento o una sola 
comparación, lejos de ir dirigido a la arbitrariedad, se instaura en orden a lograr una más justa adecuación de la pena a la verdadera entidad del hecho y a la personalidad del agente ${ }^{57}$.

En este sentido, el juicio de comparación entre las circunstancias agravantes y atenuantes posee un carácter unitario, implicando una valoración integral y obligatoria de la personalidad del agente y de la entidad global del hecho, con la consecuencia de que debe realizarse un único juicio de comparación para establecer si las agravantes concurrentes entre ellas la reincidencia- deben considerarse equivalentes a las atenuantes o por el contrario deben considerarse predominantes con respecto a estas o, en otro caso, las circunstancias atenuantes deben considerarse predominantes con respecto a las agravantes $^{58}$.

Conforme a dicho precepto, cuando en un determinado supuesto concurran al mismo tiempo circunstancias agravantes y circunstancias atenuantes, y las primeras estén consideradas por el juez como mayoritarias, no se tendrán en cuenta las disminuciones de pena establecidas para las circunstancias atenuantes, abriéndose el camino tan sólo para el aumento de la pena derivado de la concurrencia de las circunstancias agravantes; por el contrario, cuando sean las circunstancias atenuantes las que se consideren mayoritarias, no se tendrán en cuenta las circunstancias agravantes a los efectos de aumentar la pena, abriéndose el camino tan sólo a la disminución de la misma establecida para las circunstancias atenuantes concurrentes. Al mismo tiempo, si entre las circunstancias agravantes y las atenuantes el juez considera que hay equivalencia, se aplicará la pena como si no hubiera concurrido circunstancia alguna ${ }^{59}$. De todos modos esto era así, en sus términos hasta la citada reforma operada por la Ley de 5 de diciembre de 2005, n. 25I, de «Modifiche al codice penale e alla legge 26 luglio I975, n. 354, in materia di attenuanti generiche, di recidiva, di giudizio di comparazione delle circostanze di reato per i recidivi, di usura e di prescrizione», pues tras su entrada en vigor al día siguiente de su publicación en la Gazzetta Ufficiale n. 285 del 7 de diciembre 2005, se ha sustituido el inciso cuarto del artículo por otro que ahora reza así: «Le disposizioni del presente articolo si applicano anche alle circostanze inerenti alla persona del colpevole, esclusi i casi previsti dall'articolo 99, quarto comma, nonchè dagli articoli III e II2, primo comma, numero 4), per cui vi è divieto di prevalenza delle circostanze attenuanti sulle ritenute circostanze aggravanti, ed a

disminución de pena. Respecto a los supuestos de concurrencia de circunstancias homogéneas previstas en el mismo artículo y número, la jurisprudencia mayoritaria admite el concurso de circunstancias siempre que no resulten incompatibles o inconciliables no se produzcan situaciones de absorción entre ellas o no respondan a una misma razón o fundamento. Vid. ANTOLISEI, F.: Istituzioni di Diritto Penale, Ed. Giuffrè, Milano, 2000, p. 252-253; DelPINO, L.: Diritto Penale. Parte Generale, Ed. Giuridiche Simone, Napoli, 2000, p. 452-453.

57 Vid. la Cass.pen. 4.I0.82, ap. I, GP; I983, II, 223. En este sentido, la Cass.pen. 29.II.85, ap. II, GP, I987, II, 223 dispuso que: «La finalidad del juicio de comparación entre las circunstancias es la de valorar la personalidad del culpable y la verdadera entidad del hecho para conseguir la perfecta adaptación de la pena al caso concreto».

$5^{8}$ Vid. la Cass.pen. Io.II.8I, ap. II, GP, I982, II, 709 y la Cass.pen. 25.2.8I, ap. IV, GP, I982, II, 89. Hasta el D.L. de II de abril de I974, $\mathrm{n}^{\circ} 99$ (convertido en la Ley de 7 de junio de I974, $\mathrm{n}^{\circ} 220$ ) el juicio de mayoría o de equivalencia no podía tener lugar en los casos en que la ley establecía para la circunstancia una pena de especie diferente o determinaba la medida de la pena de forma independiente de la ordinaria del delito. Con el art. 6 del D.L. citado, dicho límite ha perdido eficacia, y se ha afirmado el principio opuesto, habiéndose establecido que las disposiciones según los tres primeros apartados del art. 69 se aplican a cualquier circunstancia (también a las que conciernen la persona del culpable, para las que el antiguo texto formulaba una ulterior y especifica prohibición). Cfr. Antolisei, F.: Istituzioni di Diritto Penale, op. cit., p. 253-254; DelPino, L.: Diritto Penale. Parte Generale, Ed. Giuridiche Simone, Napoli, 2000, p. 453.

59 Vid. Anolisei, F.: Istituzioni di Diritto Penale, Ed. Giuffrè, Milano, 2000, op. cit., p. 253 ss.; DelPIno, L.: Diritto Penale. Parte Generale, Ed. Giuridiche Simone, Napoli, 2000, p. 453.

Redur 4 / 2006 
qualsiasi altra circostanza per la quale la legge stabilisca una pena di specie diversa o determini la misura della pena in modo indipendente da quella ordinaria del reato».

Bibliografía

Alonso Alamo, M.: El sistema de las circunstancias del delito. Estudio general. Tesis doctoral, Universidad de Valladolid, Facultad de Derecho, I98I.

AnTOLISEI, F.: Istituzioni di Diritto Penale, Ed. Giuffrè, Milano, 2000.

Belloni, G. A.: Saggi sul Romagnosi, Ed. Fratelli Bocca, Milano, I940.

BetTiol, G.: Diritto penale, Parte Generale, $\mathrm{II}^{\mathrm{a}}$ ed., Ed. CEDAM, Padova, I982.

BRICOLA, F.: Scritti di diritto penale, a cura di Canestrari e Melchionda, vol. I, Ed. Giuffrè, Milano, I997.

CARmignani, G.: Elementi di diritto criminale, Ed. Francesco Sanvito, Milano, i863.

CARrara, F.: Lezioni sul grado della forza física del delito (conato, complicità), $6^{a}$ ed., dettate nella R. Universitá di Pisa, Lucca, Tip. Giusti, I870.

CATtAneo, N.A.: Pena diritto e dignità umana: saggio sulla filosofia del diritto penale, Ed. Giappichelli, Torino, I998.

Cerezo Mir, J.: Curso de Derecho Penal Español. Parte General. I. Introducción, Ed. Tecnos, $5^{a}$ Ed., Madrid, I996, reimpresión I997.

CotTA, S.: Gaetano Filangieri e il problema della legge, Ed.: G. Giappichelli, Torino, I954.

Delpino, L.: Diritto Penale. Parte Generale, Edizioni Giuridiche Simone, Napoli, 2000.

Del Vecchio, G.: «Giandomenico Romagnosi nel primo centenario della sua morte: discorso letto nella R. Universitá di Parma il 9 settembre I935 per il X Congresso Nazionale di Filosofia», en Rivista Internazionale di Filosofia del Diritto, $3^{a}$ ed. Roma, 1938.

De Rivacoba, M.: Elementos de Criminología, Ed. Universidad de Valparaíso, Fac. CC Jurídicas, Económicas y Sociales, Chile, 1982.

FilangieRI, G.: Ciencia de la legislación, escrita en italiano por Cayetano Filangieri, traducida al castellano por Jaime Rubio, $3^{\mathrm{a}}$ ed., corr. y añadida con discursos analíticos en cada libro, Ed. Imp. de Núñez, Madrid, I822.

García Pablos de Molina, A.: Tratado de Criminología, Ed. Tirant lo Blanch, Valencia, I999.

GARRIDO GUZMÁN, L.: «Concepto y alcance de la Criminología. Evolución Histórica y relaciones con el Derecho Penal», en Criminología y Derecho Penal, VVAA, Ed. Edijus, Zaragoza, I998.

Garrido, V.-Stangeland, P.-Redondo, S.: Principios de Criminología, Ed. Tirant lo Blanch, Valencia, I999.

GonZÁlEZ CussAC, J.L.: Teoría general de las circunstancias modificativas de la responsabilidad criminal, Ed. Servicio de Publicaciones de la Universidad de Valencia, I988.

GonZÁlez RAdio, V.: Sociología Criminal, Ed. Tórculo, Santiago de Compostela, I997. 
Herrero Herrero, C.: Criminología (Parte General y Especial), Ed. Dykinson, Madrid, 1997.

Maggiore, G.: Diritto penale. Parte generale, $5^{\mathrm{a}}$ ed., Ed. Zanichelli, Bologna, I958.

Malinverni, A.: «Circostanze del reato», en Enciclopedia del Diritto, VII, Ed. Giuffrè, Milano, I960.

Mantovani, F.: Diritto penale: Parte generale, Ed. CEDAM, Padova, I979.

MANZINI, V.: Trattato di diritto penale italiano, $5^{\text {a }}$ ed., Ed. UTET, Torino, I98I.

MASSA, M.: Le Attenuanti generiche, Ed. Eugenio Jovene, Napoli, I959.

Melchionda, A.: Le circostanze del reato Origine, Sviluppo e Prospettive di una controversa categoría penalistica, Ed. CEDAM, Padova, 2000.

Nuvolone, P.: Il Sistema del diritto penale, $2^{a}$ ed., Ed. CEDAM, Padova, I982.

Padovani, T.: Diritto Penale, Ed. Giuffrè, Milano, I990.

Pagliaro, A.: Principi di diritto penale. Parte generale, $4^{a}$ ed., Ed.: Giuffrè, Milano, I993.

Quintero Olivares, G.: Curso de Derecho Penal. Parte General, Ed. Cedecs, I ${ }^{a}$ ed., Barcelona, I996.

Rodríguez ManZAnera, L.: Criminología, Ed. Porrúa, $7^{a}$ ed., México, I991.

Romagnosi, G.D.: Genesi del diritto penale, Parte Seconda, per Francesco Sanvito, Milano, I857.

Romagnosi, G.D.: Génesis del Derecho Penal, traducción de Carmelo González Cortina y Jorge Guerrero, Ed.: Temis, Bogotá, I.956.

Romano, M.: Commentario sistematico del codice penale, V. I, $2^{\mathrm{a}}$ ed. ren. y amp., Ed. Giuffré, Milano, I995.

Rossi, P.: Tratado de derecho penal, traducido al idioma español por Cayetano Cortés, Ed. Imprenta de José María Repullés, Madrid, I839.

SpIRITO, U.: Storia del diritto penale italiano, da Cesare Beccaria ai giorni nostri, $3^{\mathrm{a}}$ ed. Firenze, I974.

ZAZA, C.: Le circostanze del reato, Vol. I, Elementi generali e circostanze comuni, Ed. Cedam, Padova, 2002.

Redur 4 / 2006 